\title{
Robust Control Applications
}

\author{
Ian Postlethwaite ${ }^{\mathrm{a}, 1}$ Matthew C. Turner ${ }^{\mathrm{a}, 1}$ Guido Herrmann ${ }^{\mathrm{a}, 1}$ \\ ${ }^{a}$ Control and Instrumentation Research Group, University of Leicester, Leicester, LE1 \\ $7 R H, U K$ \\ ixp@le.ac.uk, mct6@le.ac.uk, gh17@le.ac.uk
}

\begin{abstract}
This paper (first presented as a plenary lecture at the 5th IFAC Symposium on Robust Control Design, Toulouse, July 2006) demonstrates the practical importance of robust control theory by describing its application to two non-trivial practical control problems. Part 1 considers helicopter control and Part 2 addresses saturation problems in high-performance head-positioning servo systems in high-density hard-disk drives.

In Part 1, we present the design and flight test of a new batch of $H_{\infty}$ controllers for the Bell 205 helicopter. At the heart of each controller is an $H_{\infty}$ loop-shaping controller, augmented with a hand-tuned reference filter to improve tracking performance and to reduce a perceived phase lag which pilots had complained of previously. Flight testing revealed that, with such an architecture, it was relatively easy to get Level 1 handling qualities ratings in low aggression manoeuvres. Further fine tuning resulted in Level 1 qualities for high aggression manoeuvres and one controller performed to Level 1 standard in all manoeuvres tested.

In Part 2, we consider how robust control techniques can be used to design anti-windup compensators to counter performance and stability problems associated with saturating actuators in state-of-the-art hard-disk drive servo systems. A promising two-stage approach is given and illustrated with experimental results.
\end{abstract}

\section{Part 1: Helicopter robust controller design for Level 1 handling qualities}

\subsection{Introduction}

It is well known that helicopters are difficult aircraft to control for a variety of reasons. The four main control axes (pitch,roll,yaw and heave) are heavily coupled and exhibit dynamic behaviour which varies significantly as the helicopter moves

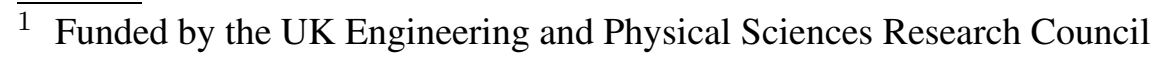


from hover to forward flight. It is difficult to model these dynamics accurately and therefore most mathematical models contain a moderate to high degree of uncertainty associated with neglected dyanamics and poorly understood aeromechanical couplings. Furthermore, rotational and translational movement of the aircraft is achieved through the main and tail rotors which contribute large time delays at the plant input, limiting the achievable closed-loop bandwidth.

In addition, the helicopter is open-loop unstable and together with the aforementioned coupling, the unaugmented aircraft requires a great deal of pilot concentration and can be fatiguing to fly, particularly in degraded visual environments and during high precision manoeuvres. Therefore, automatic controllers have been introduced to help restore stability to the aircraft and ease pilot workload. Due to the coupled nature of the aircraft, controllers designed using traditional techniques may not result in adequate decoupling and may also require extensive in-flight tuning.

This part of the paper describes the design and flight testing of a set of controllers based on $\mathcal{H}^{\infty}$ control techniques. It builds upon work reported in Postlethwaite et al. (2002) and Postlethwaite et al. (2005) where results on $\mathcal{H}^{\infty}$ control of the Bell 205 from flight tests in 2001 were reported. In turn that work progressed the work reported in Postlethwaite et al. (1999) and Walker et al. (1999) and references therein. Postlethwaite et al. (2002) and Postlethwaite et al. (2005) described several controllers which yielded Level 1 behaviour, in terms of their achieved bandwidths and, essentially, borderline Level $1 / 2$ behaviour handling qualities ratings from testpilots. Nevertheless, although successful, the pilots were not satisfied enough with the dynamic behaviour of the controllers to award level 1 handling qualities in all manoeuvres. Since those flights, there have been more flights where the problems with those tested in 2001 were addressed and many "new and improved" controllers were tested, most of which performed to Level 1 standard in the low aggression manoeuvres such as precision hover and pirouette. The work here describes the culmination of the work since 2001 and, in particular, describes two of the best controllers tested in the summer of 2004. One of these controllers performed to Level 1 standard in all manoeuvres tested.

\subsection{The helicopter}

The $\mathcal{H}^{\infty}$ controllers discussed in this paper were designed for and flight tested on the fly-by-wire Bell 205 helicopter operated by the National Research Council of Canada (NRC) Institute for Aerospace Research in Ottawa. The helicopter is equipped with a fully programmable digital flight control system capable of implementing controllers with sample rates of up to $64 \mathrm{~Hz}$. The helicopter features a dual inceptor system in which the first set of inceptors (the collective and cyclic sticks, and pedals) is operated by the evaluation pilot who generates reference demands for the flight control computer. The second set of inceptors link directly to the he- 
licopter's actuators and are monitored by a safety pilot who can can take control of the aircraft in any situation believed to be dangerous.

The helicopter is instrumented with a variety of sensors which can be used for feedback and measurement purposes. All flight test data is stored on an onboard hard-disk which can be extracted for flight test data analysis. More detail about the fly-by-wire set-up used in this set of experiments can be found in (Postlethwaite et al., 2005; Gubbels and Goheen, 1997)

\subsection{Controller Design}

\subsubsection{Model}

The model used for controller design was the same as that used for the design of the controllers reported in (Postlethwaite et al., 2002; Postlethwaite et al., 2005). The model (Howell and communication, 2001), provided by QinetiQ (formerly DERA) was a 32-state nonlinear flight mechanic model of the Bell 205. This was an improved version of the model (Strange and Howitt, 1998) used for the flight tests described in (Postlethwaite et al., 1999) and (Walker et al., 1999) and simulation results from the former model proved to be close to those obtained in-flight.

For controller design, the nonlinear model was linearised at different foward velocities with the controllers reported here being designed using low speed linearisations. The linearised models were also truncated and residualised to 13 states to prevent high order controllers resulting from the $\mathcal{H}^{\infty}$ optimisation procedure. The notable states that were removed were those assoicated with the rotor, which were replaced with their steady state values and also heading, which is discontinuous at modulo $2 \pi$ radians and because it can be expressed in terms of the rigid body states, $\theta$ and $\phi$. To capture the time delays imposed by rotor dynamics and computational effort, first order Pade approximations were introduced into all the design models.

The controllers were designed in order to control the pitch and roll attitudes, $\theta$ and $\phi$, and the yaw rate, $r$. The heave axis was left open loop, partly due to safety reasons and partly due to pilot preference as the dynamics of this channel are stable and fairly benign. The control inputs were longitudinal and lateral cyclic, which are chiefly responsible for the pitch and roll movement, respectively, and tail rotor collective, which is chiefly responsible for the yawing of the aricraft.

\subsubsection{Architecture}

The architecture used in controller design is perhaps best explained using two block diagrams. Figure 1 shows how the sensors and actuators are partitioned for controller design. The controllers here are based on decoupled models, one describing the longitudinal dynamics and one describing the lateral dynamics of the aircraft. 
This architecture was proposed in (Walker et al., 1999) and gives the designer more control over shaping the frequency response of the aircraft at the expense of losing information about the coupling between the two sets of dynamics. We adopted this architecture in this particular campaign due to the slightly greater maturity of these controller designs, although we would point out that designs which perform almost as well have been reported using the fully coupled model (Prempain and Postlethwaite, 2005).

The structures of the longitudinal and lateral controllers are shown in Figure 2. Both controllers were designed using $\mathcal{H}^{\infty}$ loop-shaping techniques, the longitudinal controller using the standard formulation of (McFarlane and Glover, 1990) and the lateral controller using the two-degrees-of-freedom (2DOF) formulation of (Limebeer et al., 1993). As the longitudinal controller was essentially a SISO controller with extra rate feedback, it was found that the standard 1DOF $\mathcal{H}^{\infty}$ loopshaping design procedure (see Skogestad and Postlethwaite (1996)) produced controllers with sufficiently good transient response and low phase-lag in the forward path (which pilots seemed sensitive to). The lateral controller was a true MIMO controller, and it was obseverved that more influence over the aircraft's transient response could be obtained using the 2DOF formulation of (Limebeer et al., 1993) (see also Skogestad and Postlethwaite (1996)), although this came at the expense of slightly increasing the phase lag observed in the forward path of the control law. In addition to the $\mathcal{H}^{\infty}$ controllers, which formed the heart of the control system, first order filters with unity steady state gain were added to the forward path to fine-tune the transient response of the vehicle.

\subsubsection{Specific controllers}

Although many different controllers were designed with several being flight tested, we concentrate on the controllers tested in the last two flight tests, mct 42 and mct 44 . These controllers are arguably the best tested in terms of pilot comment, with one of them obtaining "desired" performance in every manoeuvre.

As both controllers consisted of longitudinal and lateral parts, it was decided to base the designs of these parts around different operating points. The longitudinal controllers were designed around a $30 \mathrm{feet} / \mathrm{s}$ linearisation in order to give a trade-off between good hover and good low-speed forward flight performance. The lateral controllers were designed around the lower speed of $5 \mathrm{feet} / \mathrm{s}$. It was thought that a speed closer to hover would be more appropriate because many of the precision lateral manoeuvres are instigated from the hover and attain only very low forward speeds. It must be mentioned that previous lateral designs, which were based around the $30 \mathrm{feet} / \mathrm{s}$ oprating point, were able to perform well and that the choice of design point (either 30feet/s or 5 feet/s) had only a minor effect on performance.

The $\mathcal{H}^{\infty}$ loop-shaping design procedure allows the designer a choice of two weight- 
ing matrices, a pre-filter $W_{1}(s)$ and a post-filter $W_{2}(s)$ to shape the open-loop singular values of the plant. In all the $\mathcal{H}^{\infty}$ loop-shaping designs performed in this sequence of tests, $W_{2}(s)$ was fixed as a diagonal matrix, having the following form for the longitudinal and lateral controllers

$$
\begin{aligned}
W_{2, \text { long }} & =\operatorname{diag}(1,0.2) \\
W_{2, \text { lat }} & =\operatorname{diag}(1,1,0.2)
\end{aligned}
$$

As the outputs were ordered (see Figure 1) $\theta, q$ in the longitudinal case and $\phi, r, p$ in the lateral case, the lower value in the last diagonal entry indicates that the ratio of "proportional to derivative feedback" should be 5:1. Broadly speaking, increasing the 0.2 values would give greater damping, at the expense of more sluggish responses.

The designer was therefore left with choosing the parameters of $W_{1}(s)$ and the forward path filter $F(s)$ for both controllers, and also the model for transient response matching for the lateral controller. In the case of the longitudinal subcontroller, both $W_{1}(s)$ and $F(s)$ are scalar transfer functions. For the lateral subcontroller, the structures of $W_{1}(s), F(s)$ and the reference model, $M(s)$, are given as follows

$$
\begin{aligned}
W_{1, \text { lat }} & =\operatorname{diag}\left(W_{1, \text { roll }}, W_{1, \text { yaw }}\right) \\
F_{\text {lat }} & =\operatorname{diag}\left(F_{\text {roll }}, F_{\text {yaw }}\right) \\
M_{\text {lat }} & =\operatorname{diag}\left(M_{\text {roll }}, M_{\text {yaw }}\right)
\end{aligned}
$$

A summary of these parameters is given in Table 1 . As is normal, $W_{1}(s)$ was chosen as a proportional integral type controller to boost low frequency gain to yield good tracking performance. The refernce models, $\left(M_{\text {roll }}, M_{\text {yaw }}\right.$ were chosen as unity gain low pass filters to induce a first order type of response for the lateral dynamics. The filter $F_{\text {long }}(s)$ was chosen as a unity-gain phase-advance type filter to increase speed of response and to decrease phase lag from pilot command to aircraft response for the pitch axis. Due to the reference model, no extra filter was required in the roll axis and hence $F_{\text {roll }}=1$. During the course of the 2004 flight tests, the pilots had detected small but "irritating" yaw-roll coupling and although this was hard to eliminate within the $\mathcal{H}^{\infty}$ controller design, observation of the yaw-roll off-axis bode plot identified a high frequency "resonant" peak which was thought to be responsible for this coupling. This resonant peak was suppressed through a low pass reference filter in the yaw axis, $F_{y a w}$, although this also led to some small on-axis yaw performance deterioration as well.

Figures 3 and 4 show the output senstitivity and input co-sensitivity of the longitudinal closed-loop system. The bandwidth of the co-sensitivity is around 2-3 radians/s with the high frequency gain falling off rapidly but smoothly, meaning that the system will have good robustness to input multiplicative uncertainties which be- 
come significant beyond this point. In order to be robust to the time delays (which were about $0.2 s$ at worst) at the plant input, it was necessary to keep the bandwidth below $\approx 1 / 0.2=5$ radians/s. The sensitivity has a fairly text-book like appearance except for the upper singular value which remains above unity for almost all frequency. This singular value essentially corresponds to the the pitch-rate channel which we cannot track simultaneously with the pitch-attiude and hence is still large at low frequencies. Figures 5 and 6 tell a similar story for the lateral axes.

\subsubsection{Nonlinear Simulations}

The nonlinear simulations were carried out on the full 32-state nonlinear flight mechanic model. Building upon the simulation practices established for the work in (Postlethwaite et al., 2002), the nonlinear model was augmented with magnitude and rate-limits, controllers were discretised using Tustin's method and implemented with state-space matrices truncated to eight decimal places, anti-aliasing filters of $10 \mathrm{~Hz}$ cut-off were added and the "worst-case" time delays of $150 \mathrm{~ms}$ (in addition to the rotor dynamics) were included. All controllers were tested with gain variations in all channels of $40 \%$ across all frequencies. Over the past several years, it has been established that successful nonlinear simulation, conforming to the above rules, leads to successful flight tests. This contrasts sharply to earlier work where stabilty was not certain from test to test (Postlethwaite et al., 1999; Walker et al., 1999).

As a sample nonlinear simulation response, Figure 7 shows the roll attitude response to a pulse demand. From a first glance, the response does not seem particularly good, but as the pilots use an "overshoot" control strategy, they do not want abrupt "second order" step responses. However, note that the on-axis roll response has less than $25 \%$ coupling into other axes, which is required for Level 1 handling qualities. The control responses associated with such a pulse are shown in Figure 8 . Notice that these are relatively smooth and not abrupt ${ }^{2}$.

\subsubsection{Flight Test Results}

The flight tests described here are taken from two flights, conducted over the period of two weeks in July 2004. Due to time constraints, each controller, mct 42 and met 44 , was only tested once and, unfortunately, no flight test data is available for $\operatorname{mct} 44$, so the data for met 42 is presented.

Figure 9 shows the on-axis pitch response due to a doublet-type input in pitch attitude demand. This doublet was performed as part of the "Quick Hop" manoeuvre (see later) and hence is not a true step input. The dotted line shows the pilot demand

\footnotetext{
2 Abrupt control signals tend to lead to higher rates and "ratchety" accelerations, which
} can cause ride discomfort for the pilot 
and the solid line shows the attitude response. The jagged line depicts the pitch rate which has been filtered through a 2nd order Butterworth filter with $8 \mathrm{~Hz}$ cut-off frequency. There is good correspondence between demand and response. Note that all demands and responses have been centred around their trim values.

Figure 10 shows the on-axis roll response due to a doublet-type input in roll attitude demand. This doublet was performed as part of the "Side Step" manoeuvre (see later) and hence is not a true step input. The dotted line shows the pilot demand and the solid line shows the attitude response. The jagged line depicts the roll rate which has been filtered through a 2nd order Butterworth filter with $8 \mathrm{~Hz}$ cut-off frequency. Again there is good correspondence between demand and response, and again, all demands and responses have been centred around their trim values.

\subsubsection{ADS-33 Evaluation}

The ADS-33 standard (anonymous, 1994) is a popular measure by which helicopter handling qualities are judged and as such forms a vital part of the analysis of control law designs. We use two parts of the ADS-33 document to guide and assess our control laws: low and moderate input amplitude quantative criteria; and pilot evaluation of a series of manoeuvres desrcibed within the ADS-33 document.

\subsubsection{Quantitative analysis}

At hover, the ADS-33 quantitative criteria are, roughly speaking, separated according to input amplitude. For low amplitude inputs, the handling qualities are determined by linear-type criteria which for ACAH controllers are strong functions of the phase roll-off; for moderate amplitude inputs the handling qualities are essentially determined from the ratio of peak rate to peak attitude change. These criteria are examined below.

\subsubsection{Small amplitude responses}

Table 2 shows the bandwidths, phase delays and handling quality level induced in the aircraft by the three controllers. In previous work ((Postlethwaite et al., 2005)) we were able to show a comparison between the predictions based on linear on-axis models and flight test data. Unfortunately, due to lack of time and a flight control computer crash, frequency sweep data was not collected for either controller. Consquently, the data shown, is just that based on linear prediction. Note however, that previous research found that the correlation between predicted and achieved bandwidths and phase delay was good. 


\subsubsection{Moderate amplitude responses}

For larger inputs, the response of the helicopter is dictated by the more nonlinear nature of the aircraft's dynamics and, to cater for this, the ADS-33 document uses attitude quickness as a tool for assessing the flying qualities of the aircraft. Attitude quickness for the pitch and roll axes is defined as

$$
\text { Quickness }=\frac{\text { Peak rate }}{\text { Peak attitude change }}
$$

where the reference demand is a step input causing attiude change of at least 5 degrees. Although no true step inputs were applied during the flight tests, approximate pulses can be found for the pitch and roll axes in Figures 9 and 10. We used the first "step" to calculate attitude quickness and the corresponding ADS Level as in Table 3. Note that these ratings are somewhat below what might be expected for purely Level 1 handling qualities. Part of the reason is that the pilot demands are not true steps, so that the peak pitch and roll rates are not as great as they should be, thus leading to lower quickness ratings than expected. Also, in the ADS-33 document, the response to a step in attitude is illustrated as a second order type of response; the responses here are more first order, meaning that the peak attitude change is not quite as great.

\subsubsection{Qualitative analysis}

The ADS-33 also features a helpful qualitative examination procedure to be carried out by pilots in-flight. Past research has shown that controllers achieving good bandwidths and phase delays do not always achieve high pilot ratings. The ratings given by pilots are much more complex and include factors such as ride quality, control harmony, perceived phase-lag, nonlinearity of the response, and pilot induced oscillation susceptability.

To perform their analysis, pilots perform a series of manoeuvres which have been designed to highlight control system deficiencies. After the completion of one of these manoeuvres, the pilots "rate" the manoeuvre using handling qualities ratings (HQRs) between 1 and 10. A table showing the approximate meanings of the various HQRs is given below. The interested reader is referred to (anonymous, 1994) for more details, as Table 4 is something of a simplification, with each individual HQR having a specific meaning. Note an HQR of 1 is never awarded as it means "perfect control" and an HQR of 2 is awarded infrequently.

The following manoeuvres were performed in order to test the aircraft handling qualities:

- Quick Hop: the pilot accelerates the helicopter forward rapidly and stops abruptly 
at a given point. This is useful for testing the aggressiveness of the pitch axis and assessing the coupling into roll and yaw.

- Side-step: Similar to the Quick Hop except performed in the roll axis. Useful for testing the aggressiveness of the roll axis and assessing the coupling into pitch and yaw.

- Precision Hover: The pilot attempts to keep the helicopter in a tight hover over a given point. This is a "high gain" pilot manoeuvre and is useful for assessing control accuracy and proneness to PIOs.

- Hover Turn: This manoeuvre involves the pilot executing a 180 degree turn while at hover and mainly tests the responsiveness of the yaw axis. This is a less demanding manoeuvre than Turn-to-Target which was considered a little too aggressive for the Bell 205 helicopter.

- Pirouette: The pilot manoeuvres the helicopter around a circle of fixed radius while ensuring that the helicopter's nose faces towards the centre of the circle and that no loss in height occurs.

Table 5 shows the results of the pilot's handling qualities assessments. Note that controller met 44 achieves Level 1 handling qualities in all manoeuvres. The only differences between the two controller designs are that (i) the bandwidth of met 44 was lowered slightly by using a slightly slower model in the $2 \mathrm{DOF} \mathcal{H}^{\infty}$ loopshaping procedure and (ii) the rise-time of the pitch axis of met 44 was increased using more phase advance in the reference filter. This was because the pilots seemed very sensitive to "pitch roll harmony"; they sometimes felt the aircraft was slightly too abrupt in pitch compared to roll or vice versa. In fact throughout much of the flight tests conducted between the 2001 results reported in (Postlethwaite et $a l ., 2002$ ) and (Postlethwaite et al., 2005) and these 2004 results, only fine tuning of parameters was needed in order to push the handlinq qualities from HQR 4 to HQR 3, much of it aimed at harmonising the pitch and roll axes.

\subsection{Conclusions}

This paper has described the design and flight testing of two $\mathcal{H}^{\infty}$ controllers designed to bestow desirable handling qualities on the NRC Bell 205 helicopter. These controllers were two of the "best" of about a dozen controllers tested between 2001 and 2004. Over the course of these flight tests it was found that robust stability and adequate (Level 2) handling qualities were relatively easy to achieve using $\mathcal{H}^{\infty}$ techniques It was more difficult, however, to tune the controllers to achieve desirable (Level 1) handling qualities, although most of the re-tuning which was necessary was conducted on a variety of on-axis reference filters, outside of the main control loop.

It was also noticed that quantitative ratings implying good flying qualities do not always lead to good pilot ratings, and that those implying poorer handling qualities 
may not always lead to poor pilot ratings. Thus the controllers met 42 and met 44 were fine-tuned mainly using pilot comments. This suggests that some refinement of the ADS-33 criteria might be required to allow more harmony between handling qualities ratings awarded in flight test and those predicted on the basis of simulation or experimental data.

\subsection{Acknowledgements}

The authors would like to thank S.E. Howell and A.T. McCallum from QinetiQ (formerly DERA) Bedford for helpful discussions regarding the Bell 205 model and flight tests. Thanks go also to E. Prempain and E. Turkoglu at the University of Leicester, who were both involved with the earlier flight tests. Finally thanks go to K. Ellis and A.W. Gubbels and the pilots, R. Erdos, S. Carnnigan and T. Lesley, at the NRC Institude for Aerospace Research, Ottawa, for managing and performing the flight tests.

\section{Part 2: Improvements in dual-stage hard disk drive servo systems}

\subsection{Introduction}

Hard disk drives (HDDs) are responsible for the data storage on virtually all the world's modern desktop computers. Their storage capacity has increased tremendously over the past twenty years, with capacities of 200GB now common place. Accompanying this increase in storage capacity and track density has been the need to improve the HDD-servo systems and corresponding control laws. Traditionally, the positioning of the HDD read/write head was accomplished using a voice coil motor (VCM) actuator but now, with the higher data rates being sought, researchers have begun to look at methods for improving this approach. Amongst the promising contenders is so-called dual-stage servo control. In this approach, the conventional VCM actuator is augmented with a second high bandwidth micro actuator which can respond faster than its more cumbersome VCM counterpart. A popular type of secondary microactuator is the PZT-based actuator, for example the 'FUMA'actuator (Tokuyama et al., 2001) and recent years have seen a great deal of research activity in this area (see Mori et al. (1991) or Kobayashi et al. (2001)).

In terms of servo-control, the dual-stage actuator has to deal with the following servo-tasks: seek/settling and track following. Seek/settling control has to ensure a fast movement of the read/write head from one track to another using a non-linear time-optimal controller. For track following, linear high bandwidth controllers are necessary to ensure good error rejection capabilities for counteracting disturbances. 
In particular, seeking over long spans has been problematic in dual-stage control (when the distance between the current and the demanded track is large). It requires controller scheduling techniques which combine servo-control tasks: seek/settling and track following (e.g. Mori et al. (1991), Kobayashi et al. (2001), Guo et al. (2002) or Messner (2005)). This is problematic due to the non-linear constraints of the two actuators.

Recently, techniques have been devised which can overcome these problems (Hredzak et al. (2005), Hredzak et al. (2006)). One of the issues with the secondary PZT actuator is that its displacement range is very limited, typically less than $1-2 \mu \mathrm{m}$, and due to its fragility, the input voltage which drives this actuator is also limited. Thus the general approach is to allow the low bandwidth VCM actuator to dominate the slower large amplitude portion of the control law and to use the secondary actuator to improve the faster, lower amplitude portion. However, due to the variety of tasks which the read/write head must perform (seek/settling and track following) it is not always possible to achieve all of these tasks with one linear control law and actuator saturation commonly occurs. In fact, for high performance, one can expect a dual-stage control system to experience control signal saturation in both actuators for certain tasks. As with many systems, actuator saturation can induce undesirable transient behaviour in the dual-stage servo system, compromising the system's performance. The low displacement PZT actuator is particularly prone to saturation and several papers have appeared addressing this issue e.g. Guo et al. (2002) and Messner (2005), which have reported improved behaviour using various "anti-saturation" techniques. However, during demanding tasks, the VCM actuator may also saturate leading to degraded performance and several papers have appeared addressing both actuator constraints (Hredzak et al. (2005), Hredzak et al. (2006) Herrmann et al. (2004b)) where formal guarantees of the system's stability were given. Of particular interest is the paper Herrmann et al. (2004b) in which the dual-stage system's behaviour during saturation is improved through an antiwindup (AW) scheme. These results were seen as useful as the period of secondary actuator saturation was reduced for short span seeking tasks, and the resulting reduced settling time allowed swift resumption of track following. However, results reported in this paper were not sufficiently good to allow long-span seeking as performance was not sufficient during primary VCM-actuator control signal saturation. Recently, a long and short span seeking/settling and track-following method for dual-stage control systems was presented by Hredzak et al. (2005) and Hredzak et al. (2006). However, a trade-off in this method is the limitation which is caused by a saturation non-linearity in the secondary actuator loop. The respective controller for the secondary loop is designed in one step with the constraint of satisfying the circle criterion during this design step. Thus it would appear attractive to combine the approaches of Hredzak et al. (2006) with those of Herrmann et al. (2004b) to overcome the limitation of the circle criterion in the one-step design approach and to guarantee fast settling. Thus the approach this paper takes is to advocate the appealing two-stage approach to dealing with actuator saturation: 
i) Design a controller for the secondary loop ignoring saturation (and thus ignoring the Circle Criterion)

ii) Augment this with an AW compensator to guarantee overall stability and to improve performance during saturation.

This removes some of the conservatism of Hredzak et al. (2006) and, as the aim of the AW technique is to provide a swift return to linear operation, ensures that the nominal control law is disrupted as little as possible. The AW ideas presented are a combination of those introduced in Turner et al. (2003), Herrmann et al. (2003) and Herrmann et al. (2006b)) and Turner et al. (2004) and are reported in more detail in Herrmann et al. (2006a)

\subsection{A robust discrete anti-windup compensator scheme}

The AW scheme we will consider is given in Figure 12 where

$$
\begin{gathered}
{\left[\begin{array}{l}
z \\
y
\end{array}\right]=\left[\begin{array}{cc}
G_{11} & G_{12} \\
G_{21} & \tilde{G}_{22}
\end{array}\right]\left[\begin{array}{l}
d \\
u
\end{array}\right]} \\
\tilde{G}_{22}=G_{22}(z)+W_{22}(z) \Delta(z)
\end{gathered}
$$

is the generalised plant and $G_{22}$ is the nominal component of the plant while $W_{22}$ is the frequency weighting of the additive uncertainty $\Delta(z)$, an unknown stable bounded transfer function. The exogenous signal $d$ represents the disturbances, $u$ represents the control inputs, $y$ the measurement, $z$ the performance output and $K$ is the controller. Without control signal saturation the system is well-posed and robustly stable with respect to $W_{22}(z) \Delta(z)$ in a small gain sense, and it is assumed that the nominal open-loop plant is asymptotically stable ${ }^{3}$. The AW compensator becomes active, through the linear component $\Theta(z)$ if saturation occurs. This representation is fairly general but not easy to analyse. A more convenient scheme, as introduced by Weston and Postlethwaite (1998), is shown in Figure 13, where the AW compensator is parameterised in terms of $M(z)$. As can be seen in Herrmann et al. (2004a), Figure 13 can be re-drawn as Figure 14 which exhibits a decoupling into nominal linear system, disturbance filter and nonlinear loop. Notice that because of the additive uncertainty, $W_{22}(z) \Delta(z)$, the decoupling is not complete.

The nonlinear operator

$$
\mathcal{T}_{z r}: u_{\text {lin }} \mapsto\left[\begin{array}{c}
z_{d} \\
u_{r}
\end{array}\right]
$$

$\overline{3}$ A requirement for global finite gain stability results in this case 
is central to robust performance optimisation. The mapping (Herrmann et al., 2006a)

$$
\mathcal{T}_{z}: u_{l i n} \mapsto z_{d},
$$

describes the performance degradation the system experiences in terms of the performance output $z$ during saturation. Furthermore, it has been shown by Turner et al. (2004) that the control system with AW-compensation cannot be more robust than the nominal control system as the minimal $\mathcal{L}_{2}$-gain of

$$
\mathcal{T}_{r}: u_{\text {lin }} \mapsto u_{r}
$$

is one. The $\mathcal{L}_{2}$-gain of the operator $\mathcal{T}_{z r}$ is therefore an important measure for AW compensation. In practice, it is more appropriate to minimise the $\mathcal{L}_{2}$-gain of a weighted version

$$
\tilde{\mathcal{T}}_{z r}: u_{l i n} \mapsto\left[\begin{array}{c}
W_{p} z_{d} \\
W_{r} u_{r}
\end{array}\right]
$$

This allows a trade-off between performance and robustness using the diagonal matrices $W_{p}>0$ and $W_{r}>0$. More details of this AW scheme can be found in the papers of Herrmann et al. (2004b), Turner et al. (2003), Herrmann et al. (2003), Herrmann et al. (2006b), Turner et al. (2004), Herrmann et al. (2004a).

\subsection{A dual-stage seek/settle/track-following scheme}

Figure 15 shows a simplified version of the control scheme of Hredzak et al. (2005) and Hredzak et al. (2006). It uses a decoupled track-following servo system similar to Kobayashi and Horowitz (2001) but with a nonlinear track-seek, track-following scheme to regulate the position of the VCM-actuator tip. For this purpose, we use Proximate Time Optimal Servo (PTOS) control which is a well established servocontrol method for VCM-actuators allowing an almost ('proximate') time-optimal seeking process (Franklin et al., 1990). Furthermore, the secondary loop will use a state feedback controller combined with a compensator $C_{C O M P}$. This will ensure that track-following performance is dominated by the high bandwidth actuator and that stability is retained.

A simplified block diagram of the control scheme of Hredzak et al. (2005) and Hredzak et al. (2006) is shown in Figure 15. It is based on the decoupled trackfollowing servo system by Kobayashi and Horowitz (2001). In contrast to Kobayashi and Horowitz (2001), a nonlinear track-seek, track-following scheme is used to regulate the position of the VCM-actuator tip. Here, the Proximate Time Optimal Servo (PTOS)-control scheme will be used. Furthermore, the secondary loop uses a state feedback controller combined with a compensator $C_{C O M P}$ which ensures that track-following performance is dominated by the high bandwidth actuator and stability is retained despite using the circle criterion for the introduced saturation nonlinearity $\left(S_{1}\right)$. 
Implementation. In reality, the representation of the control scheme proposed in Hredzak et al. (2006) and depicted in Figure 15 is a simplification of the scheme used in practice. In fact, in order for the scheme to work satisfactorily various additions have to be made to the control law. Firstly, notch filters are added to both loops in order to compensate for high frequency resonances present in both actuators. This is particularly important for the VCM actuator loop because the PTOS controller has been developed under the assumption that the VCM actuator is an ideal double integrator when in reality it exhibits large high frequency resonances which are problematic for the PTOS scheme. These notch filters are placed at the input of both actuators meaning that the plant "seen" by the controller is in fact

$$
\left[\begin{array}{c}
P_{V C M s} \\
P_{P Z T s}
\end{array}\right]=\left[\begin{array}{c}
P_{V C M} C_{V C M / N o t c h} \\
P_{P Z T} C_{P Z T / N o t c h}
\end{array}\right]
$$

where $C_{P Z T / N o t c h}$ and $C_{V C M / N o t c h}$ are the zero-order-hold transfer functions of the notch filters for the PZT and VCM actuators, respectively. For notch filters which are carefully matched to the plant, both $P_{P Z T s}$ and $P_{V C M s}$ can be accurately approximated by second order transfer functions.

Notice that in the control scheme depicted in Figure 15 the PZT loop requires the position of the PZT actuator for feedback. In practice, this is not available and thus it is estimated using an observer. This observer, designed for the fourth order model $\left[\begin{array}{c}P_{V C M s} \\ P_{P Z T s}\end{array}\right]$, is used in conjunction with a bias force observer to counteract the bias force $u_{d}$ caused by the VCM-flex cable.

Assuming a second order double integrator model of $P_{V C M s}$, the PTOS-scheme can be designed using a nonlinear function $f(\cdot)$ and a state feedback gain $\left[k_{v 1} k_{v 2}\right]$. The practically implemented control scheme is presented in Figure 16. The PZT-control loop is a combination of a state-feedback controller using the gain $-\left[k_{P 1} k_{P 2}\right]$ and a compensator $C_{C O M P}$. Both controllers are designed so that the PZT-actuator improves the high-frequency controller response, while the low frequency range is dominated by the VCM-control loop. In addition, a saturation nonlinearity, $S_{1}$, is introduced into the PZT loop to ensure that the the PZT actuator never saturates, i.e. the limits of the saturation elements $\left(S_{3 / a}\right)$ and $\left(S_{3 / b}\right)$ are never reached. The saturation limits for $\left(S_{2 / a}\right)$ are tuned to ensure the saturation limits of $\left(S_{2 / b}\right)$ are never reached. The saturation, $S_{1}$, effectively limits the magnitude of the error signal passed to the PZT controller although its presence constrains the design of the PZT controller through the Circle Criterion. Therefore, the observer is suitable for the, effectively linear, system $\left[\begin{array}{c}P_{V C M s} \\ P_{P Z T S}\end{array}\right]$. More details of this control scheme can be found in Hredzak et al. (2005) and Hredzak et al. (2006). 
The large-span seek/settle/track-following scheme introduced by Hredzak et al. (2005) and Hredzak et al. (2006) operates well and with a large bandwidth, once the scheme is in track-following mode. However, the saturation, $S_{1}$, introduced in the PZT to protect the actuator from saturation, may cause problems. The first is that slow settling features may result from this architecture because saturation is effectively tackled at the error input rather than at its source, the control input. Also, as the linear controller $\left(-\left[k_{P 1} k_{P 2}\right]\right.$ and $\left.C_{C O M P}\right)$ is designed to ensure nonlinear stability via the Circle Criterion, it may be difficult to find a controller which satisfies this while adhering to the bandwidth specifications. Essentially, this architecture requires the linear controller to meet both performance and saturation tolerance in one step.

In order to remedy these problems, we suggest removing the saturation $\left(S_{1}\right)$ and introducing an AW-compensator for the saturation $\left(S_{3 / a}\right)$. This implies that the linear controller for the PZT can be designed to its linear specification on bandwidth and the AW compensator can be used to handle any saturation problems. In this way, it is expected that the large-span seek performance will be retained but with improved settling behaviour and overall robust stability of the entire system. A diagram of the modified control scheme is shown in Figure 17. The design of the AW-compensator is based on $\left[\begin{array}{c}P_{V C M s} \\ P_{P Z T s}\end{array}\right]$.

\subsection{Experimental results}

To evaluate the AW compensator, we used a HDD-dual-stage system including a commercial VCM-actuator (with mechanical resonances at $4.97 \mathrm{kHz}, 6.6 \mathrm{kHz}, 9.8$ $\mathrm{kHz}$ and $13.1 \mathrm{kHz}$ ), and a 'FUMA' PZT-actuator (with resonances at $6.6 \mathrm{kHz}, 9.8$ $\mathrm{kHz}, 12.3 \mathrm{kHz}, 20.4 \mathrm{kHz}$ and $33.7 \mathrm{kHz}$ ). A Laser-Doppler-Scanning-Vibrometer (LDV) was used to measure position and the sampling time was $T_{s}=1 / 27,000 \mathrm{sec}$.

\subsubsection{Track-following control and linear nominal control}

During track following, or in the case of small track seek step demands, amplitudes are small and the control scheme is essentially linear. The linear scheme has been tuned to have an open loop crossover frequency of about $2 \mathrm{kHz}$, a phase margin of about $35^{\circ}$ and a gain margin of about $4 \mathrm{~dB}$. The phase margin determines a peak high frequency amplitude of about $10 \mathrm{~dB}$ for the sensitivity response. Figure 18(a) shows the respones to a step of about $200 \mathrm{~nm}$. Settling times of about $0.6 \mathrm{~ms}$ are achieved for the nominal linear controller. 


\subsubsection{Small span seeking control}

With small step demands of about $200 \mathrm{~nm}$, the AW control scheme (Section 2.4) recovers the linear nominal control behaviour, as none of the signals is constrained by a saturation nonlinearity. In contrast, the control scheme with the saturation nonlinearity $\left(S_{1}\right)$ as suggested by (Hredzak et al., 2005; Hredzak et al., 2006) results in a saturated signal at $\left(S_{1}\right)$. For the small $200 \mathrm{~nm}$ step demand, the result is that the nominal linear controller is modified, reducing the 'derivative kick', so that any overshoot is reduced and the settling time decreases from $0.6 \mathrm{~ms}$ to $0.4 \mathrm{~ms}$.

\subsubsection{Medium span seeking control}

For medium span seeking steps only the secondary PZT-control loop saturates. This means that either any signal passing saturation $\left(S_{1}\right)$ is reaching the limits for Hredzak's scheme or that the AW-compensator is active for saturation $S_{3 / a}$. The step response to a $4 \mu \mathrm{m}$ step is shown in Figure 19. Table 6 shows the faster settling times, $t_{s}$, of the AW-compensation scheme compared to original scheme of Hredzak et al. (2005).

Table 6 also shows the time, $t_{r}$, needed to recover from saturation in the secondary loop. In Figure 19(b), which shows the response of the system with AW compensation, because saturation is measured at $S_{3 / a}, t_{r}$ can be directly determined from the graphs. In Figure 19(a), which shows the response of the system using Hrezdak's original approach, the saturation of interest is $S_{1}$ and any signal which saturates at $S_{1}$ will be filtered by the compensator $C_{C O M P}$. Thus $t_{r}$ is also shown on this figure although it does not correspond to any recovery from "physical" saturation. In general, the AW-scheme recovers faster from a saturated signal in the PZT-control loop, allowing linear behaviour to resume sooner. Note the control effort for the VCM-actuator control signal (see channel 1 of Figure 19) is very small in amplitude, and the oscillations are mainly due to measurement noise (the measurement scale is $200 \mathrm{mV}$ per unit for channel 1).

\subsubsection{Large span seeking control}

In this situation, both actuator signals reach their saturation limits and the PTOSscheme is active for the VCM-control loop, as can be seen in Figure 20. For these large seek steps, the settling times approach similar values for each of the investigated approaches, as seen in Table 6.

However, it is clear that the optimization based AW-compensation method recovers from PZT saturation about $1.6 \mathrm{~ms}$ faster, enabling linear track following to resume earlier. 


\subsection{Conclusions}

The purpose of this Part 2 has been to show how robust control techniques can be used to design anti-windup compensators to alleviate problems associated with saturating actuators. The treatment has focussed on the performance of HDD-servo systems. An appealing two-stage approach has been given and illustrated with experimental results.

\subsection{Acknowledgments}

The authors are grateful to Dr Branislav Hredzak and Dr Guoxiao Guo of the A*Star Data Storage Institute who collaborated on this work and also co-authored (Herrmann et al., 2006a) which gives a fuller treatment of the dual-stage results.

\section{References}

anonymous (1994). Handling Qualities Requirements fo Military Rotorcraft, Aeronautical Design Standard ADS-33D. United States Army ATCOM, St. Louis, MO.

Franklin, G. F., J. D. Powell and M . L. Workman (1990). Digital Control of Dynamic Systems. 2nd ed.. Addison-Wesley Publishing Company, Reading, Massachusetts.

Gubbels, A.W. and K.R. Goheen (1997). Digital re-design of the Bell 205 airborne simulator artificial feel system. Canadian Aeronautics and Space Journal.

Guo, G., D. Wu and T. C. Chong (2002). Dealing with secondary actuator saturation in dual stage hdd servo. In: Prepr. of the 2nd IFAC Conf. Mechatr. Systems, Berkeley, USA. pp. 769-774.

Herrmann, G., B. Hredzak, M. C. Turner, I. Postlethwaite and G. Guo (2006a). Improvement of a novel dual-stage large-span track-seeking and track-following method using anti-windup compensation. In: Proceedings of the 2006 American Control Conference, Minneapolis, Minnesota, USA.

Herrmann, G., M. C. Turner and I Postlethwaite (2004a). Some new results on anti-windupconditioning using the Weston-Postlethwaite approach. In: Proceedings of the 43rd Conference on Decision and Control, Bahamas, USA.

Herrmann, G., M. C. Turner and I. Postlethwaite (2006b). Discretetime and sampled data antiwindup synthesis: stability and performance. Intern. J. Systems Science 37(2), 91113.

Herrmann, G., M. C. Turner, I. Postlethwaite and G. Guo (2004b). Practical implementation of a novel anti-windup scheme in a hdd-dual-stage servo-system. IEEE/ASME Transactions on Mechatronics 9(3), 580-592. 
Herrmann, G., M.C. Turner and I. Postlethwaite (2003). Discrete time anti-windup - part 2: extension to sampled data case. In: Proc. of the European Control Conf.

Howell, S. and A. McCallum Private communication (2001).

Hredzak, B., G. Herrmann and G. Guo (2005). Short and long-span track seek control for hard disk drive dual-stage servo actuators. In: Proceedings of IEEE Industrial Electronics Society Conference, Raleigh, North Carolina.

Hredzak, B., G. Herrmann and G. Guo (2006). A proximate-time-optimal-control design and its application to a hard disk drive dual-stage actuator system. IEEE T. Magnetics, accepted.

Kobayashi, M. and R. Horowitz (2001). Track seeking control for hard disc dual-stage servo systems. IEEE Trans. Magnetics 37(2), 949-954.

Kobayashi, M., S. Nakagawa, T. Atsumi and T. Yamaguchi (2001). High-bandwidth servo control designs for magnetic disc drives. In: Proc. IEEE/ASME Intern. Conf. Adv. Intel. Mechatr., Como, Italy. pp. 1124-1129.

Limebeer, D.J.N., E.M. Kasenally and J.D. Perkins (1993). On the design of robust twodegree-of-freedom controllers. Automatica 29(1), 157-68.

McFarlane, D.C. and K. Glover (1990). Robust Controller Design Using Normalised Coprime Factor Plant Descriptions. Vol. 138. Lecture Notes in Control and Information Sciences, Springer Verlag.

Messner, W. (2005). Modified pq method for robustness to microactuator saturation and failure. In: Proceedings of the IFAC World Congress, Prague, Czechia.

Mori, K., T. Munemoto, H. Otsuki, Y. Yamaguchi and K. Akagi (1991). A dual-stage magnetic disk drive actuator using a piezoelectric device for high track density. IEEE Transactions on Magnetics 27(6), 5298-5300.

Postlethwaite, I., A. Smerlas, D.J. Walker, A.W. Gubbels, S.W. Baillie, M.E. Strange and J. Howitt (1999). $\mathcal{H}^{\infty}$ control of the NRC Bell 205 fly-by-wire helicopter. Journal of the American Helicopter Society 44(4), 276-284.

Postlethwaite, I., E. Prempain, E. Turkoglu and M.C. Turner (2002). Various $\mathcal{H}^{\infty}$ controllers for the bell 205: design and flight test. IFAC World Congress.

Postlethwaite, I., E. Prempain, E. Turkoglu, K. Turner, M.C.and Ellis and A.W. Gubbels (2005). Design and flight testing of various $\mathcal{H}^{\infty}$ controllers for the bell 205 helicopter. Control Engineering Practice 13, 383-398.

Prempain, E. and I. Postlethwaite (2005). Static $\mathcal{H}^{\infty}$ loopshaping of a fly-by-wire helicopter. Automatica 41(9), 1517-1528.

Skogestad, S. and I. Postlethwaite (1996). Multivariable Feedback Control: Analysis and Design. Wiley. Chichester, UK.

Strange, M.E. and J. Howitt (1998). The configuring of helisim to represent the flight dynamics of the nrc bell 205 helicopter. DERA internal report. 
Tokuyama, M., T. Shimizu, H. Masuda, S. Nakamura, M. Hanya, O. Iriuchijima and J. Soga (2001). Development of a $\phi$-shaped actuated suspension for 100-ktpi hard disk drives. IEEE Transactions on Magnetics 37(4), 1884-1886.

Turner, M. C., G. Herrmann and I. Postlethwaite (2003). Discrete-time anti-windup: Part 1 - stability and performance. In: Proceedings of the European Control Conference, Cambridge, UK.

Turner, M. C., G. Herrmann and I. Postlethwaite (2004). Accounting for uncertainty in anti-windup synthesis. In: Proceedings of the American Control Conference, Boston, USA.

Walker, D.J., M.C. Turner, A. Smerlas, A.W. Gubbels and M.E. Strange (1999). Robust control of the longitudinal and lateral dynamics of the Bell 205 helicopter. Proc. American Control Conference 4, 2742-2726.

Weston, P.F. and I Postlethwaite (1998). Analysis and design of linear conditioning schemes for systems containing saturating actuators. IFAC Nonlinear Control System Design Symposium. 


\section{Tables}

Table 1

Controller tuning parameters

\begin{tabular}{|l|l|l|}
\hline Parameter & Controller 1 & Controller 2 \\
\hline$W_{1, \text { long }}$ & $2 \frac{s+1}{s}$ & $2 \frac{s+1}{s}$ \\
$W_{1, \text { roll }}$ & $1.2 \frac{s+0.5}{s}$ & $1.2 \frac{s+0.5}{s}$ \\
$W_{1, \text { yaw }}$ & $1.5 \frac{s+1}{s}$ & $1.5 \frac{s+1}{s}$ \\
$M_{1, \text { roll }}$ & $\frac{1}{0.31 s+1}$ & $\frac{1}{0.34 s+1}$ \\
$M_{1, \text { yaw }}$ & $\frac{1}{0.23 s+1}$ & $\frac{1}{0.23 s+1}$ \\
$F_{\text {long }}$ & $1+\frac{0.65 s}{0.5 s+1}$ & $1+\frac{0.7 s}{0.4 s+1}$ \\
$F_{\text {roll }}$ & 1 & 1 \\
$F_{\text {yaw }}$ & $\frac{5}{s+5}$ & $\frac{5}{s+5}$ \\
\hline
\end{tabular}


Table 2

Handling qualities

\begin{tabular}{|c|c|c|c|c|}
\hline \multirow[t]{2}{*}{ Controller } & \multirow[t]{2}{*}{$\mathrm{B} / \mathrm{W}$} & \multirow[t]{2}{*}{$\mathrm{P} / \mathrm{D}$} & \multicolumn{2}{|c|}{ Hand. Quality } \\
\hline & & & Combat & Other \\
\hline \multicolumn{5}{|l|}{ Pitch } \\
\hline $\operatorname{mct} 42$ & 2.1252 & 0.0683 & 1 & 1 \\
\hline $\operatorname{mct} 44$ & 2.3748 & 0.0644 & 1 & 1 \\
\hline \multicolumn{5}{|l|}{ Roll } \\
\hline $\operatorname{mct} 42$ & 3.6477 & 0.0730 & 1 & 1 \\
\hline $\operatorname{mct} 44$ & 3.5166 & 0.0744 & 1 & 1 \\
\hline \multicolumn{5}{|l|}{ Yaw } \\
\hline $\operatorname{mct} 42$ & 1.3764 & 0.0797 & 3 & 2 \\
\hline $\operatorname{mct} 44$ & 1.3796 & 0.0790 & 3 & 2 \\
\hline
\end{tabular}


Table 3

Approximate Quickness ratings from flight test (mct 42)

\begin{tabular}{|c|c|c|c|}
\hline \multirow[t]{2}{*}{ Axis } & \multirow[t]{2}{*}{ Quickness } & \multicolumn{2}{|c|}{ HQ Level } \\
\hline & & Target acquisition & Other MTE's \\
\hline Pitch & $10 / 25=0.40$ & 2 & 1 \\
\hline Roll & $23 / 22=1.05$ & 3 & 2 \\
\hline
\end{tabular}


Table 4

Interpretation of HQRs

\begin{tabular}{|l|l|l|}
\hline HQR & Approximate description & Flying quality \\
\hline $1,2,3$ & Desirable aircraft performance & 1 \\
$4,5,6$ & Adequate aircraft performance & 2 \\
$7,8,9$ & Inadequate aircraft performance & 3 \\
10 & Aircraft unflyable & n/a \\
\hline
\end{tabular}


Table 5

HQR ratings

\begin{tabular}{|l|l|l|}
\hline Manoeuvre & \multicolumn{2}{|c|}{ HQR Rating } \\
& mct 42(28th July) & mct 4 4 (30th July) \\
\hline QH & 3 & 3 \\
SS & 4 & $3_{+}$ \\
PH & 3 & $3-$ \\
HT & 3 & 3 \\
PIR & 2 & 2 \\
\hline
\end{tabular}


Table 6

Settling time $t_{s}$ and time $t_{r}$ for recovery from saturation [ms]

\begin{tabular}{|c||c|c|c|c|}
\hline \multicolumn{1}{|c||}{ Step Size } & \multicolumn{2}{c|}{$\begin{array}{c}\text { Hredzak } \text { et al. (2006) } \\
\text { scheme }\end{array}$} & \multicolumn{2}{|c|}{$\begin{array}{c}\text { Scheme } \\
\text { with AW }\end{array}$} \\
\hline & $t_{s}$ & $t_{r}$ & $t_{s}$ & $t_{r}$ \\
\hline $0.2 \mu \mathrm{m}$ & 0.4 & not measurable & 0.6 & no sat. \\
$4 \mu \mathrm{m}$ & 1.9 & 1.9 & 1.4 & 1.4 \\
$8 \mu \mathrm{m}$ & 2.3 & 2.4 & 2 & 2 \\
$20 \mu \mathrm{m}$ & 2.6 & 3.2 & 2.5 & 2.6 \\
$80 \mu \mathrm{m}$ & 2.6 & 3.4 & 2.6 & 3.2 \\
$200 \mu \mathrm{m}$ & 2.1 & 4.3 & 2 & 2.7 \\
\hline
\end{tabular}




\section{Figure captions}

Figure 1 De-coupled architecture

Figure 2 Controller structure

Figure 3 Longitudinal axis output sensitivity

Figure 4 Longitudinal axis input co-sensitivity

Figure 5 Lateral axis output sensitivity

Figure 6 Lateral axis input co-sensitivity

Figure 7 Nonlinear simulation of response to roll attitude pulse demand: mct 44

Figure 8 Nonlinear simulation of control response to roll attitude pulse demand: met 44

Figure 9 Quick Hop response: controller met 42

Figure 10 Side step response: controller met 42

Figure 11 Schematic of Hard Disk Drive with PZT-FUMA-actuator

Figure 12 A general anti-windup configuration for robust stability

Figure 13 Conditioning with $M(z)$

Figure 14 Equivalent representation of conditioning with $M(z)$

Figure 15 Simplified seek/settle/track-following scheme of Hredzak et al. (2006)

Figure 16 Complete control scheme of Hredzak et al. (2006) with observer

Figure 17 Modified control scheme with observer and AW-compensation

Figure 18 Step response of $200 \mathrm{~nm}$; ch3(top): LDV-measurement $(2 \mu \mathrm{m} / \mathrm{V})$, ch2(middle): PZT-amplifier input, ch1(bottom): VCM-driver input

Figure 19 Step response of $4 \mu m$; ch3(top): LDV-measurement $(2 \mu \mathrm{m} / \mathrm{V})$, ch2(middle): PZT-amplifier input, ch1(bottom): VCM-driver input

Figure 20 Step response of $200 \mu m$; ch3(top): LDV-measurement $(20 \mu \mathrm{m} / \mathrm{V})$, ch2(middle): PZT-amplifier input, ch1(bottom): VCM-driver input 


\section{Figures}

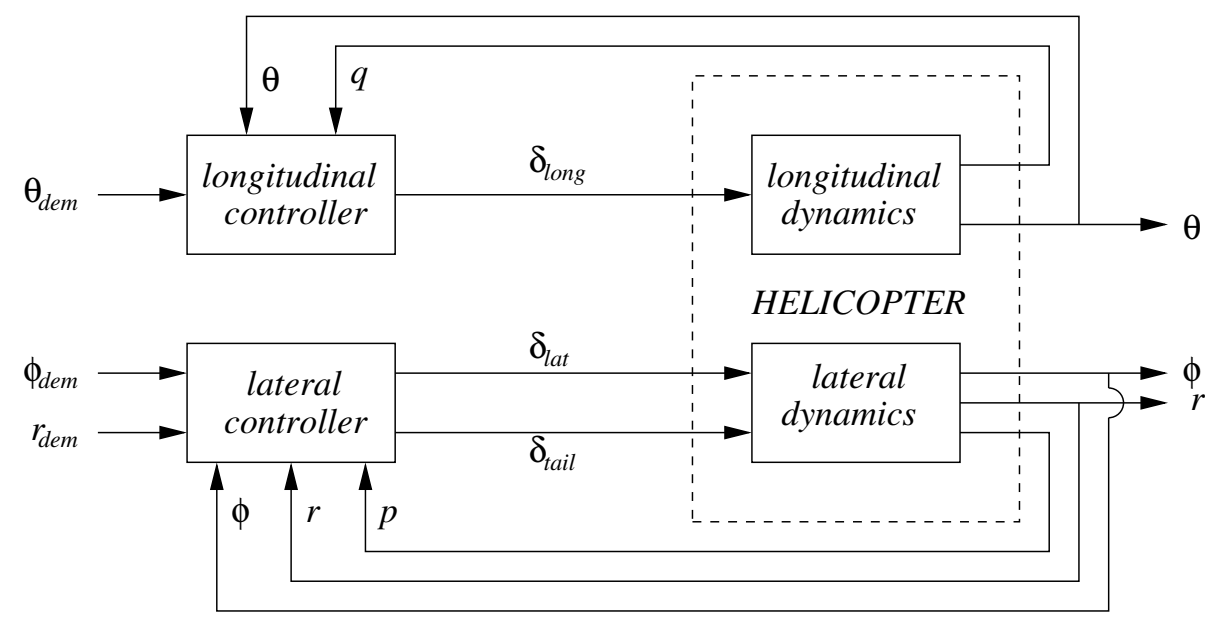

Fig. 1. De-coupled architecture 


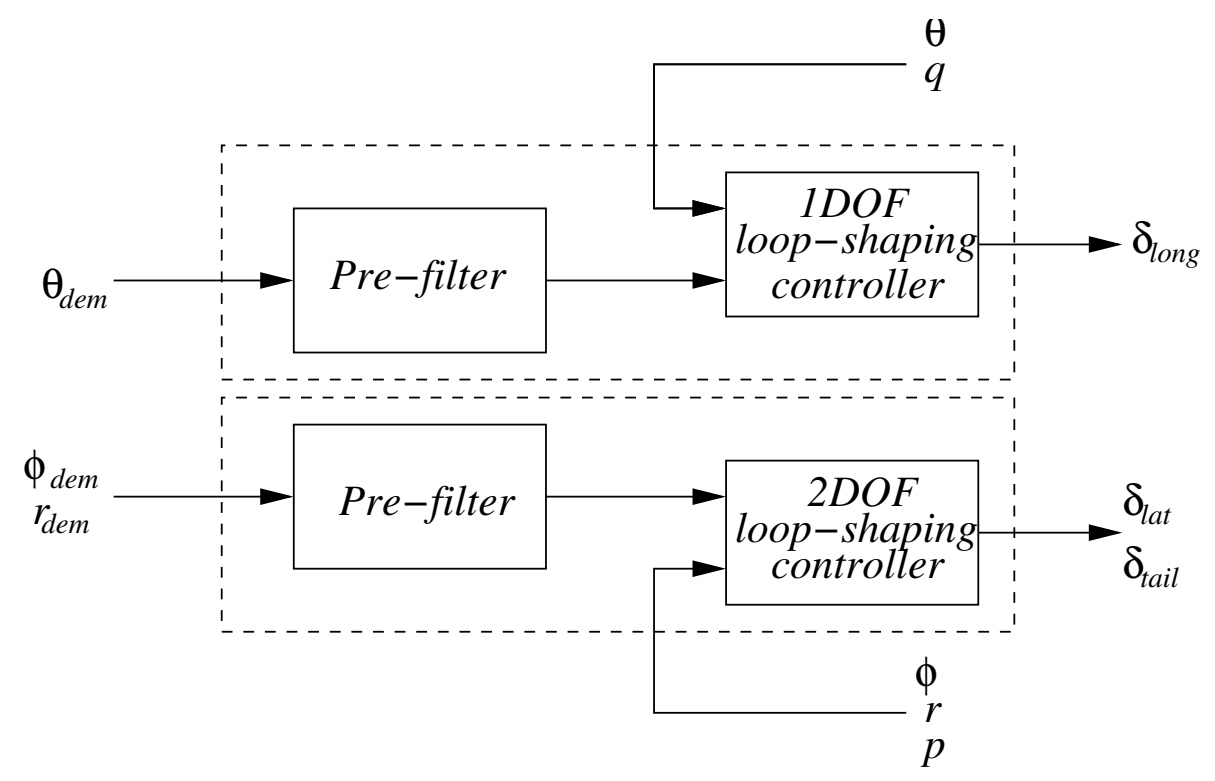

Fig. 2. Controller structure 


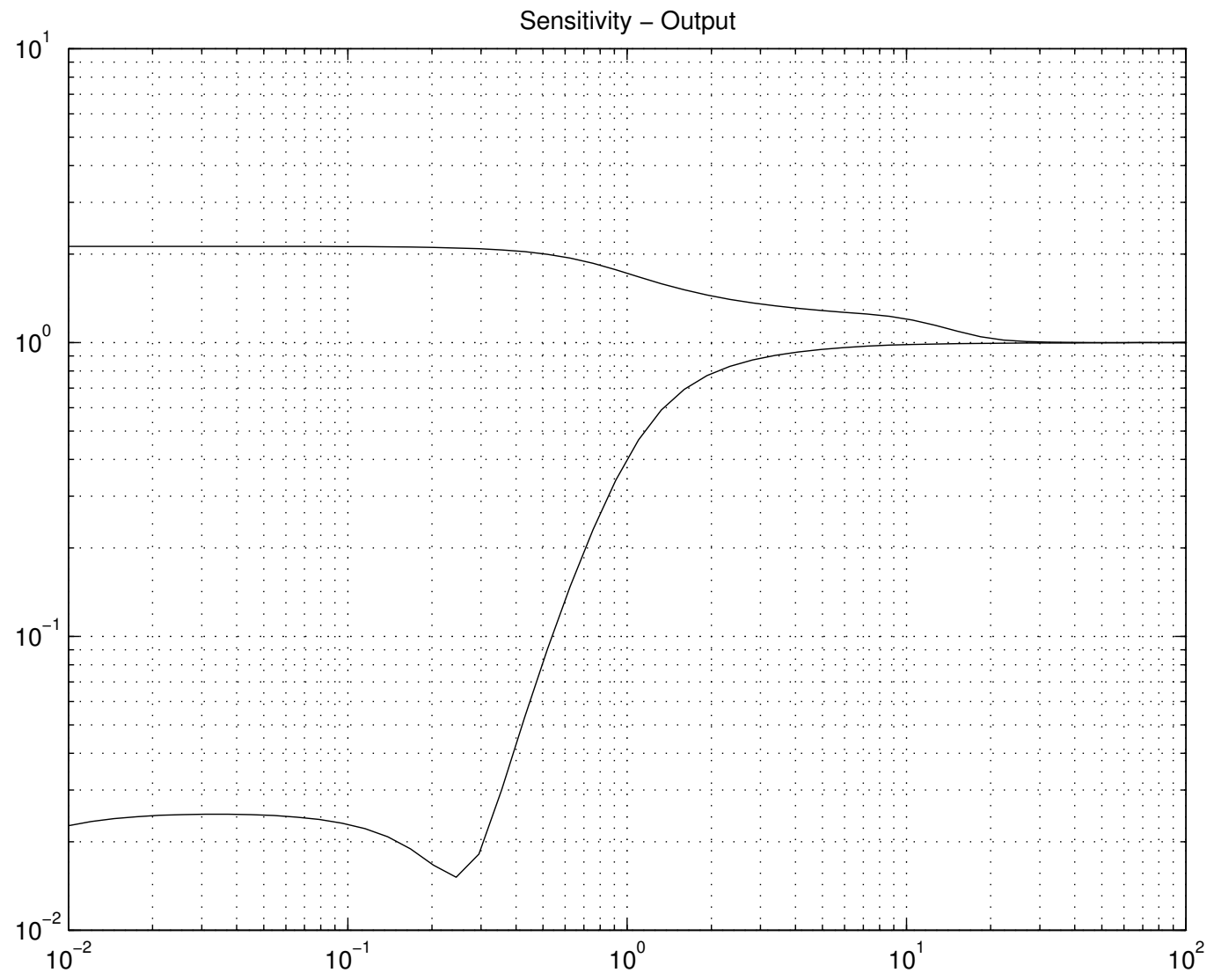

Fig. 3. Longitudinal axis output sensitivity 


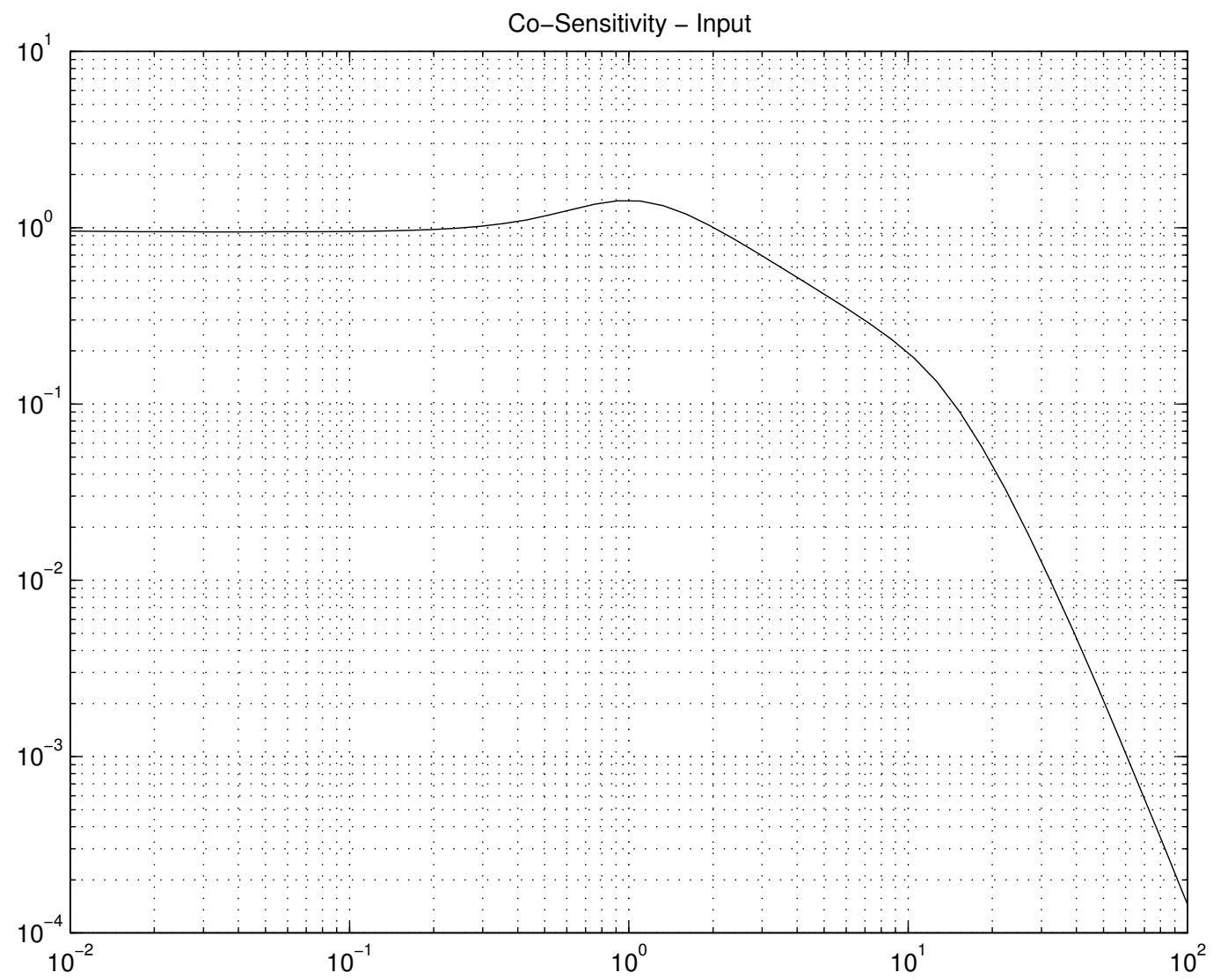

Fig. 4. Longitudinal axis input co-sensitivity 


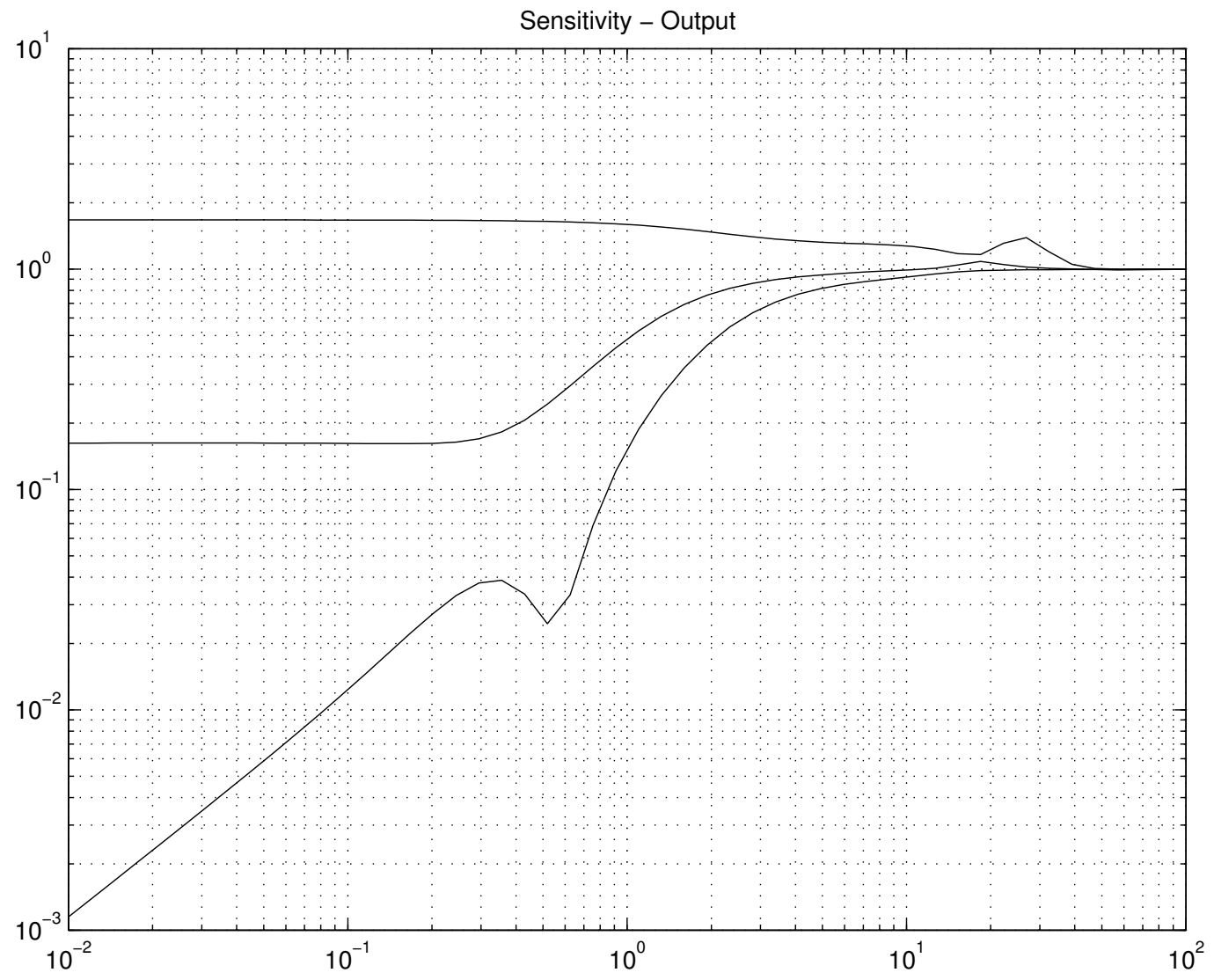

Fig. 5. Lateral axis output sensitivity 


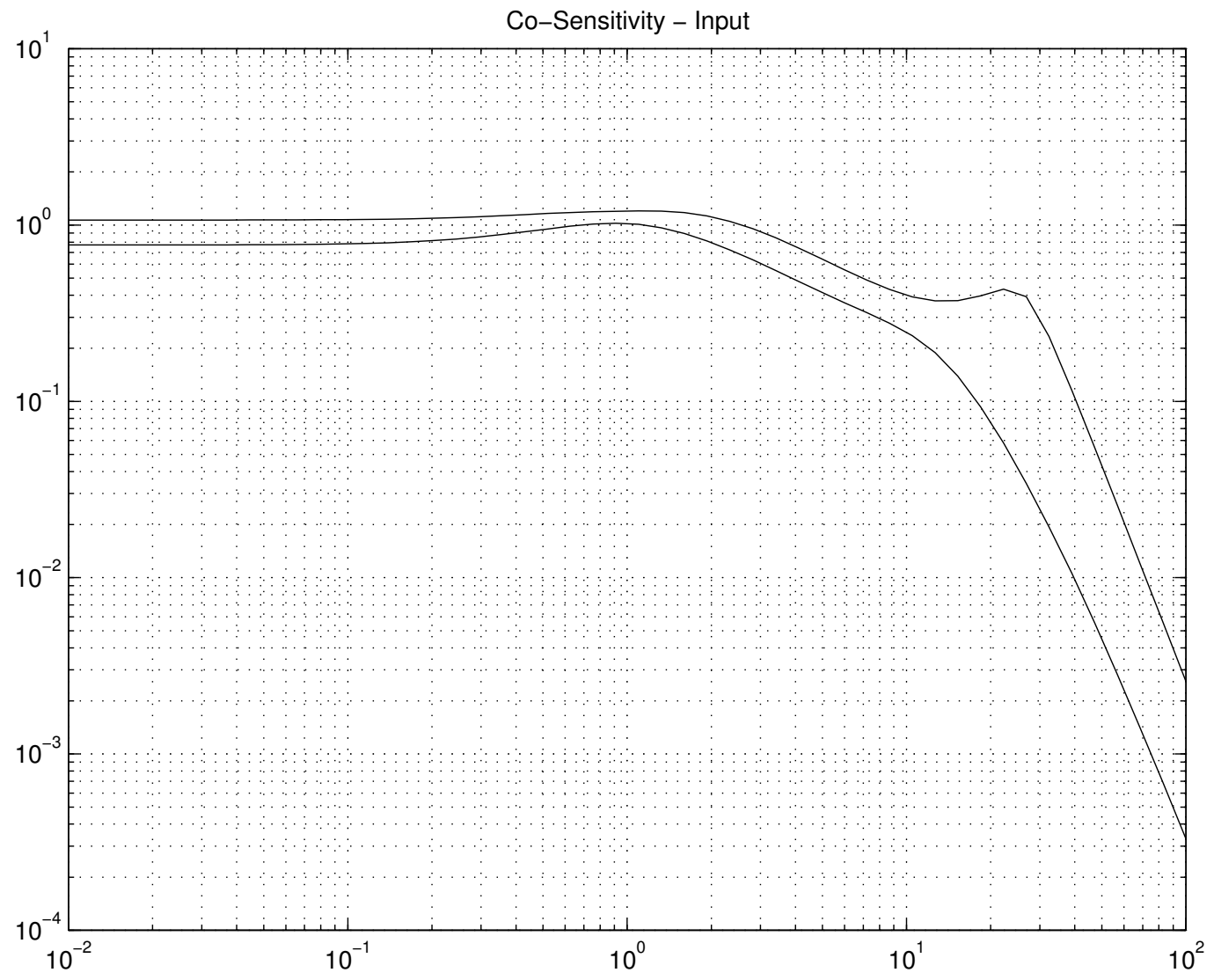

Fig. 6. Lateral axis input co-sensitivity 


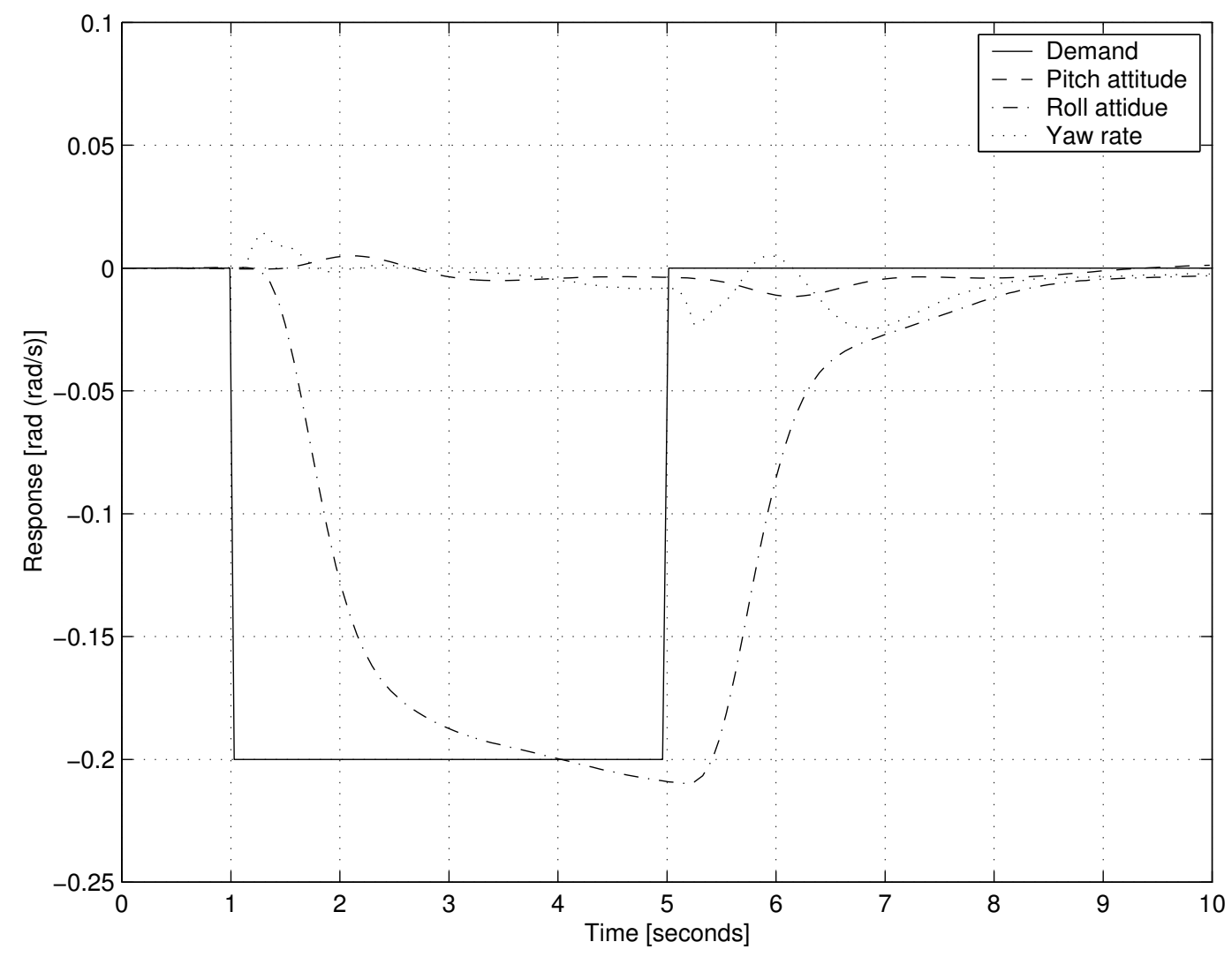

Fig. 7. Nonlinear simulation of response to roll attitude pulse demand: met 44 


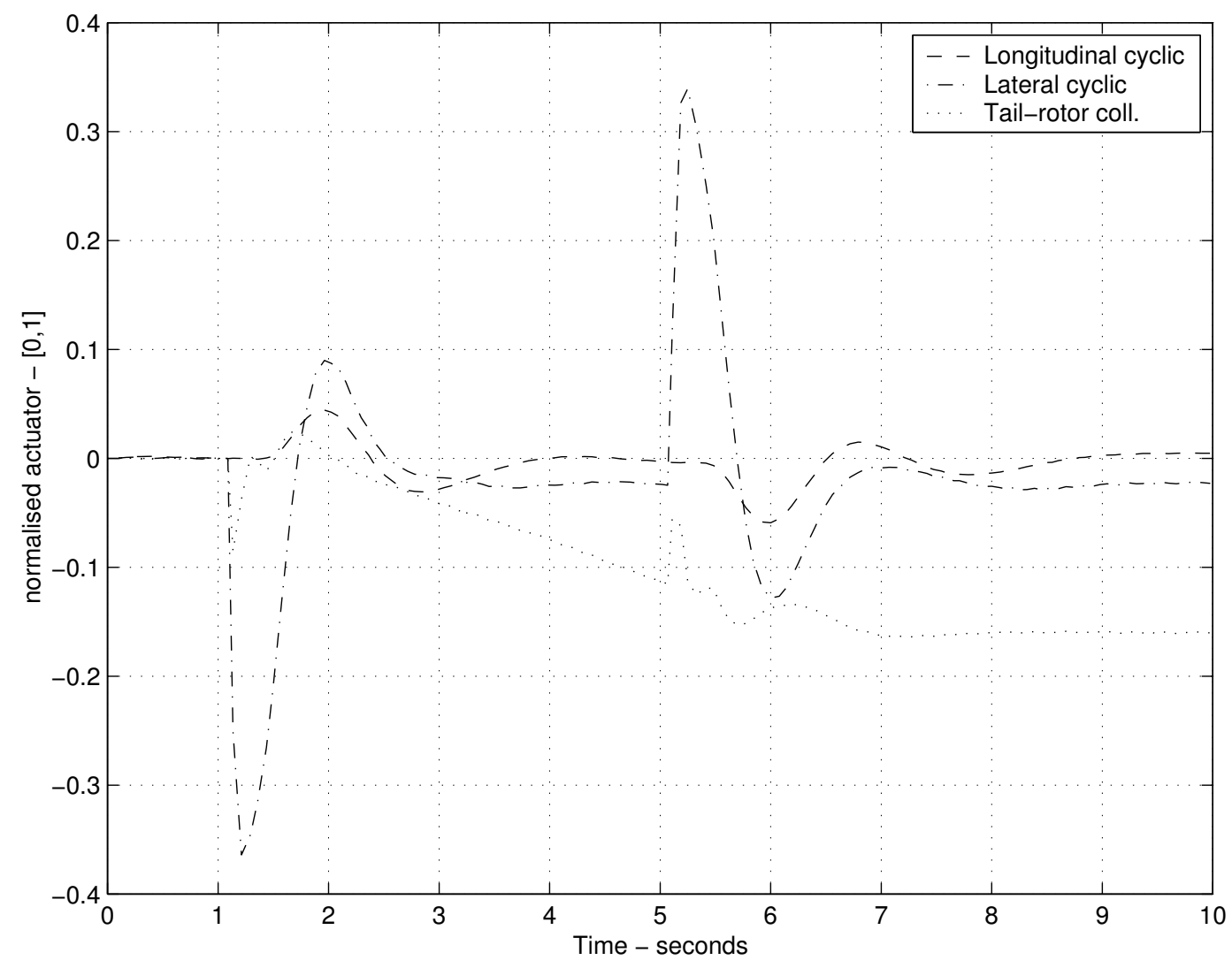

Fig. 8. Nonlinear simulation of control response to roll attitude pulse demand: met 44 


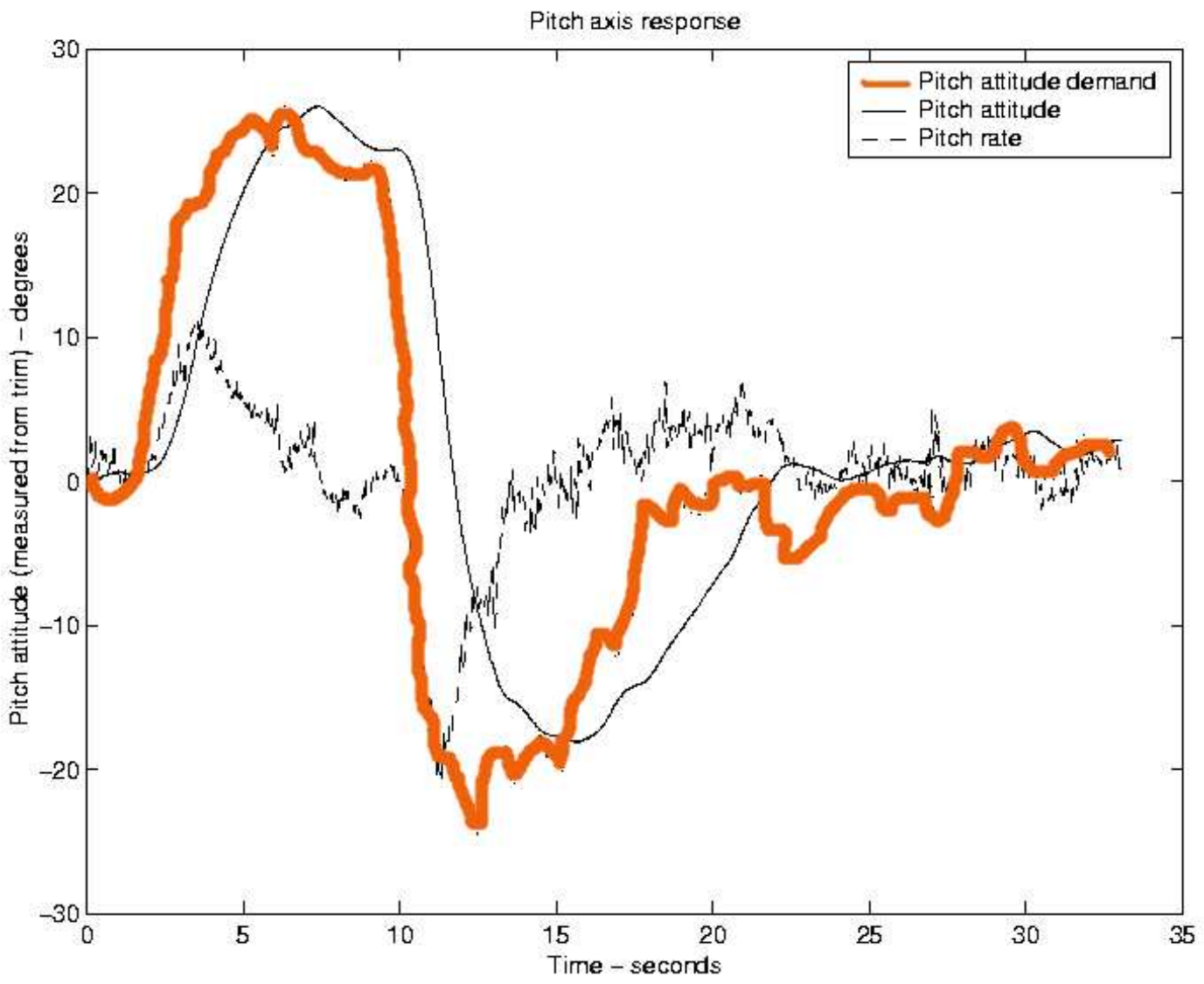

Fig. 9. Quick Hop response: controller met 42 


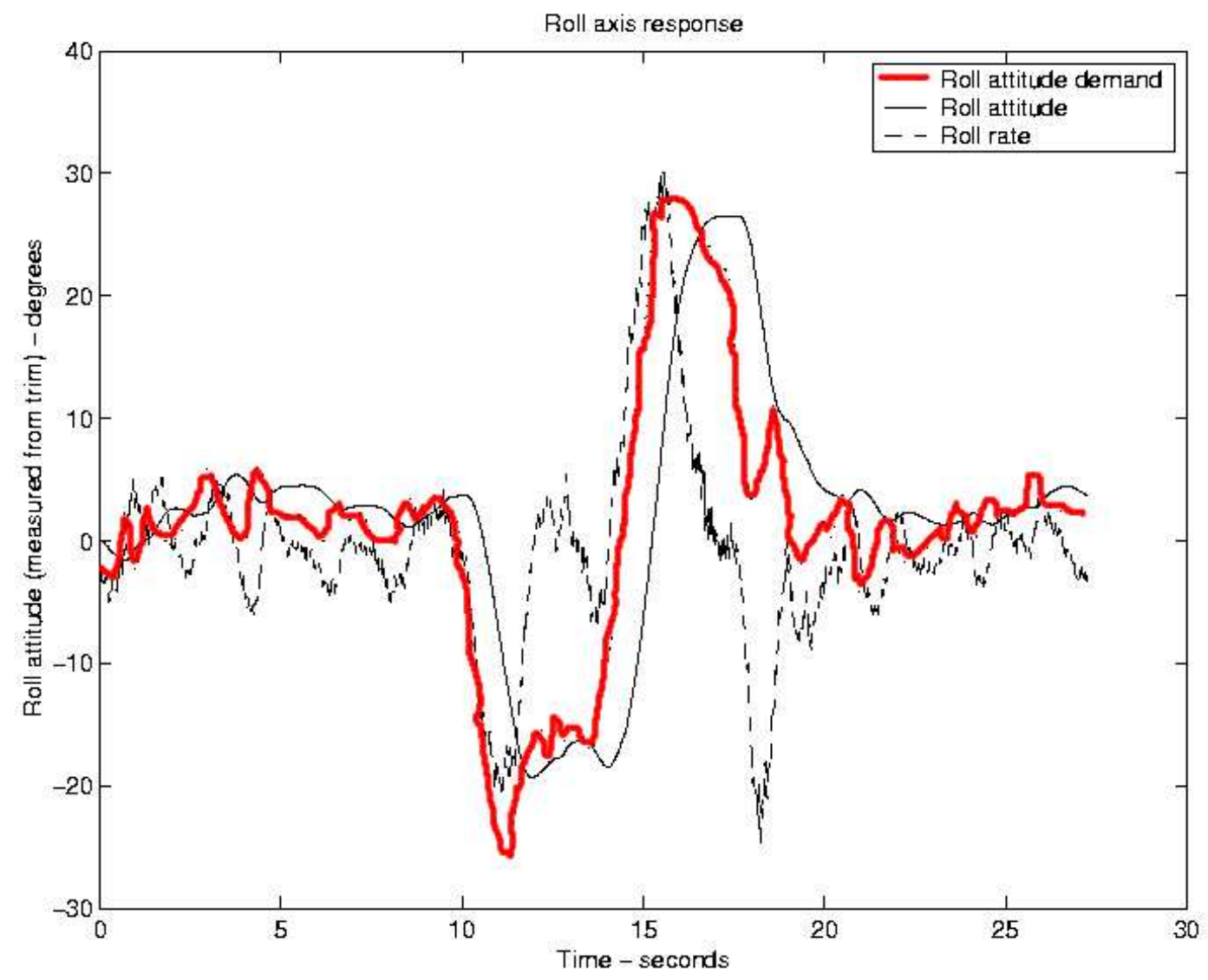

Fig. 10. Side step response: controller met 42 


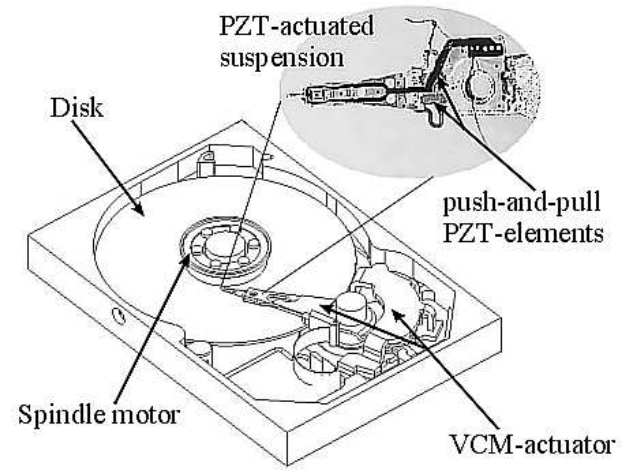

Fig. 11. Schematic of Hard Disk Drive with PZT-FUMA-actuator 


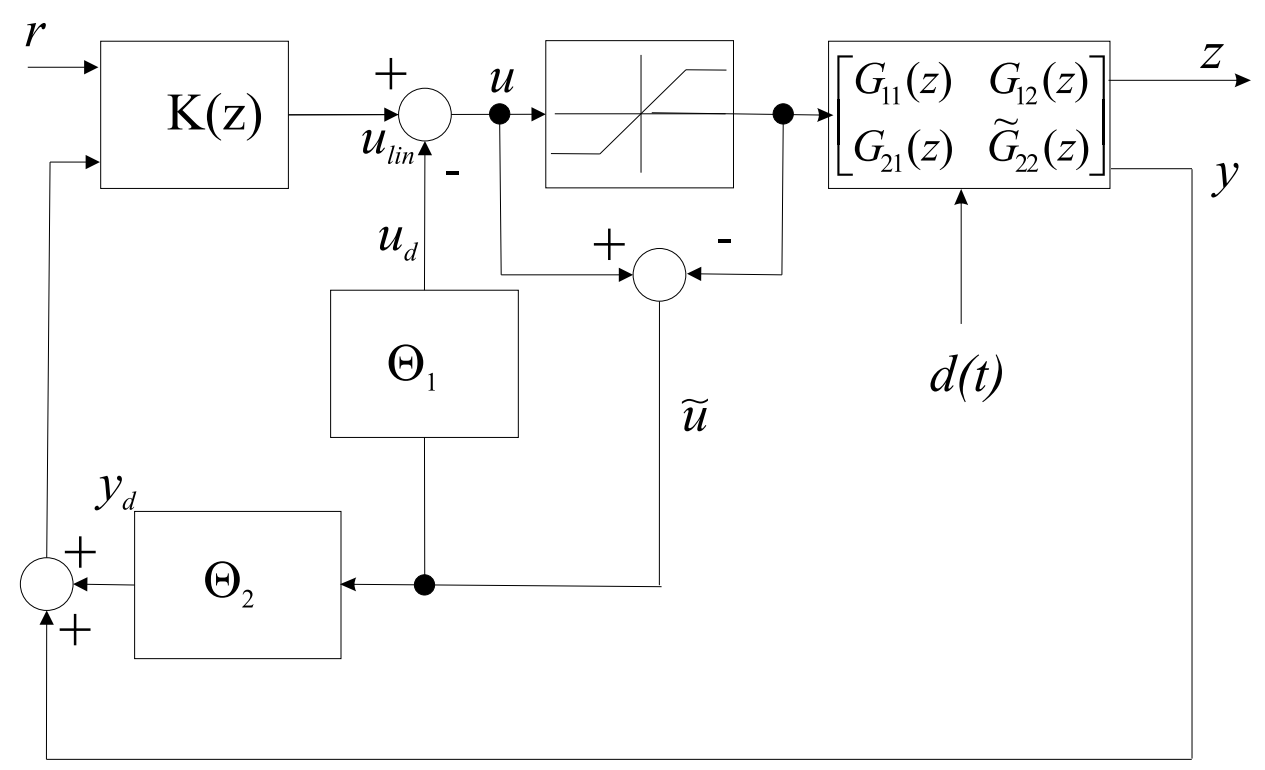

Fig. 12. A general anti-windup configuration for robust stability 


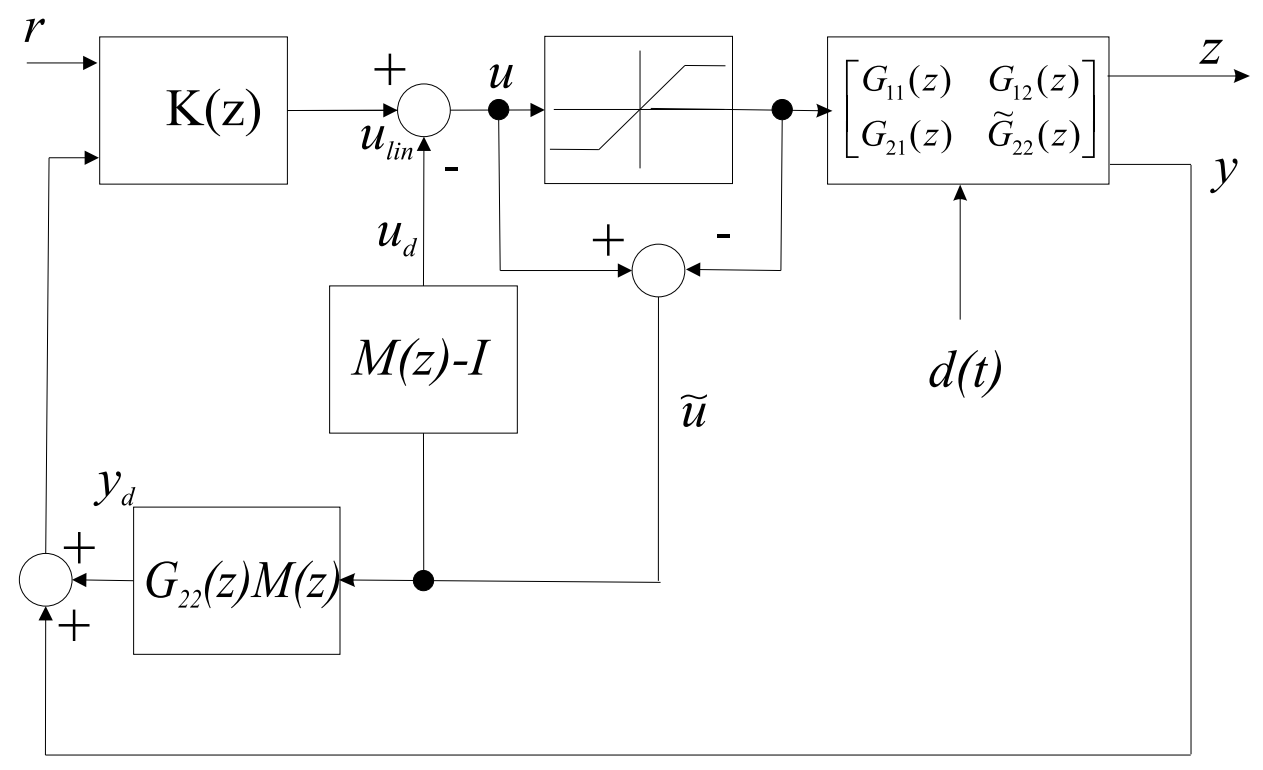

Fig. 13. Conditioning with $M(z)$ 


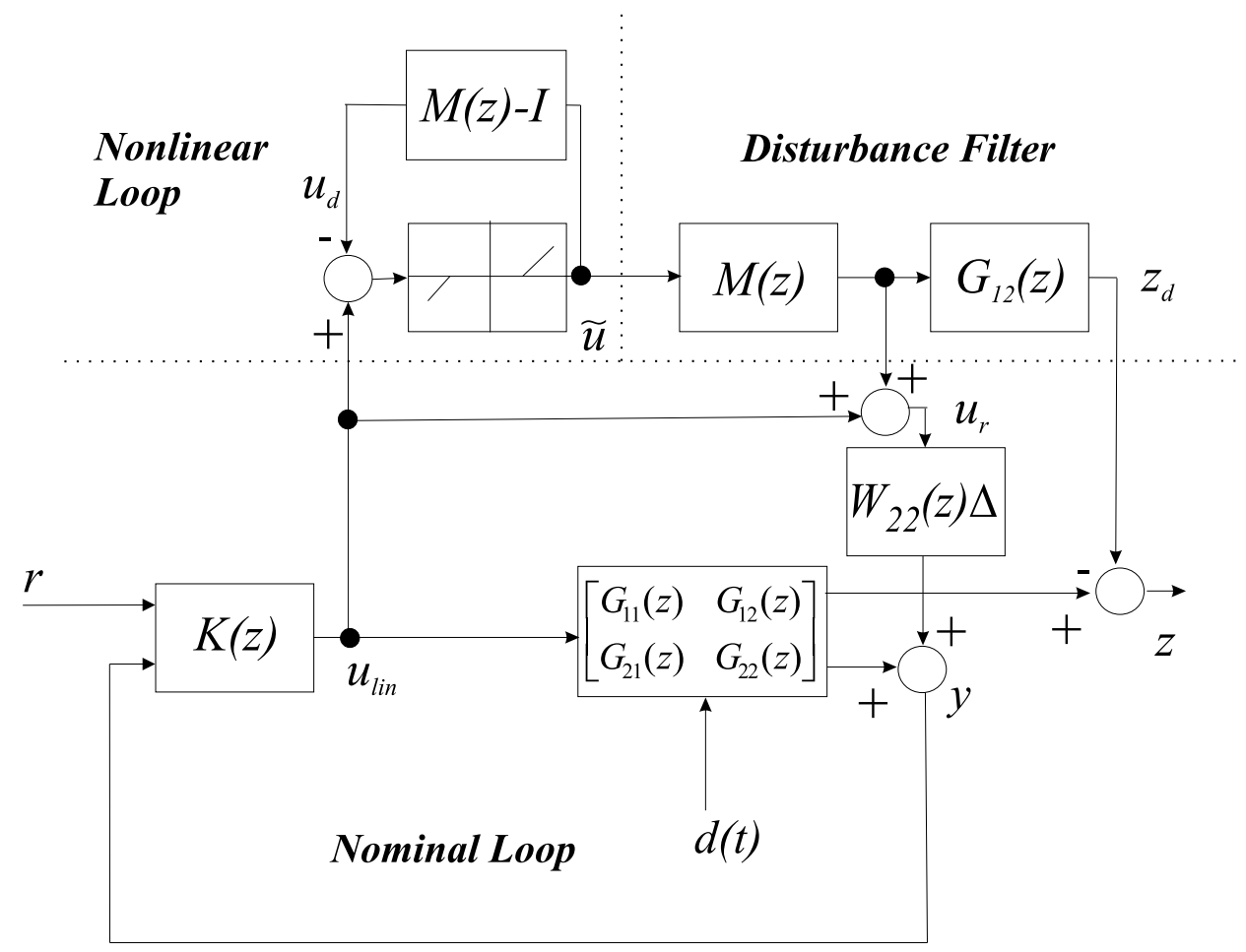

Fig. 14. Equivalent representation of conditioning with $M(z)$ 


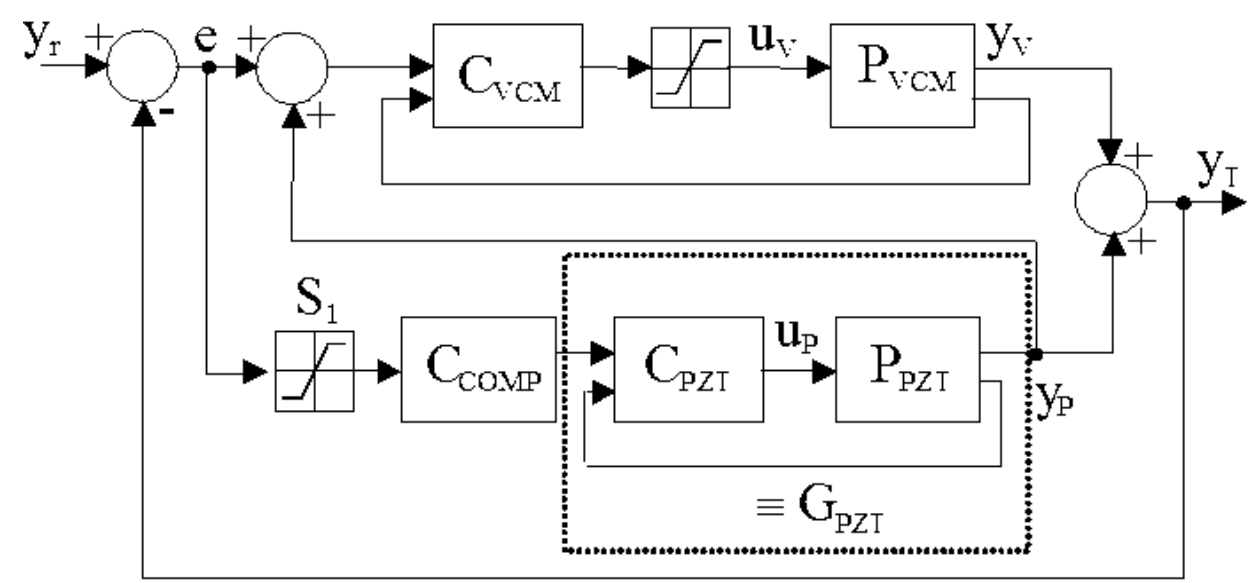

Fig. 15. Simplified seek/settle/track-following scheme of Hredzak et al. (2006) 


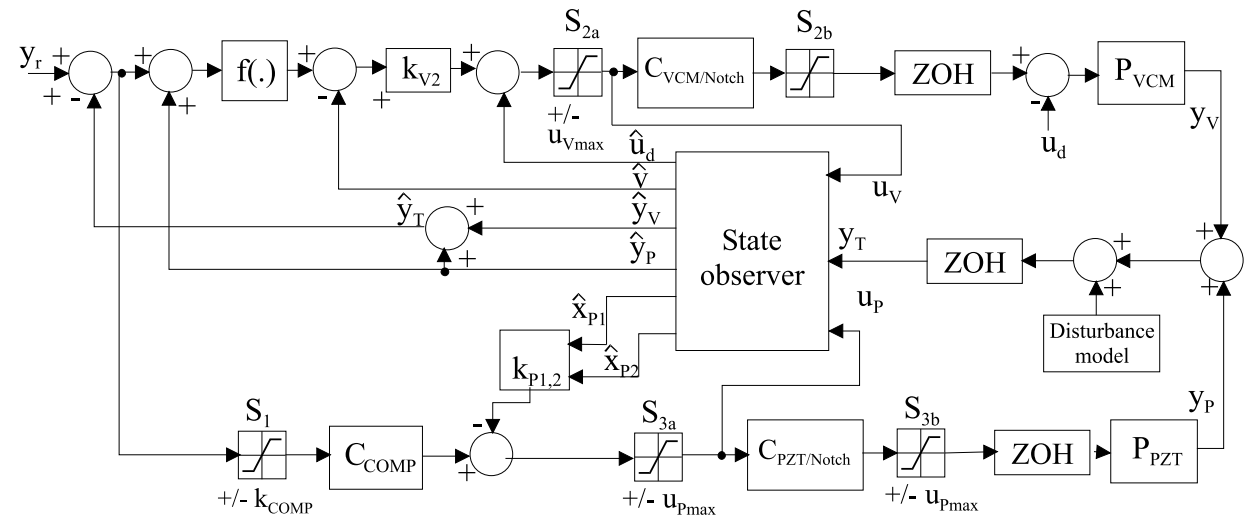

Fig. 16. Complete control scheme of Hredzak et al. (2006) with observer 


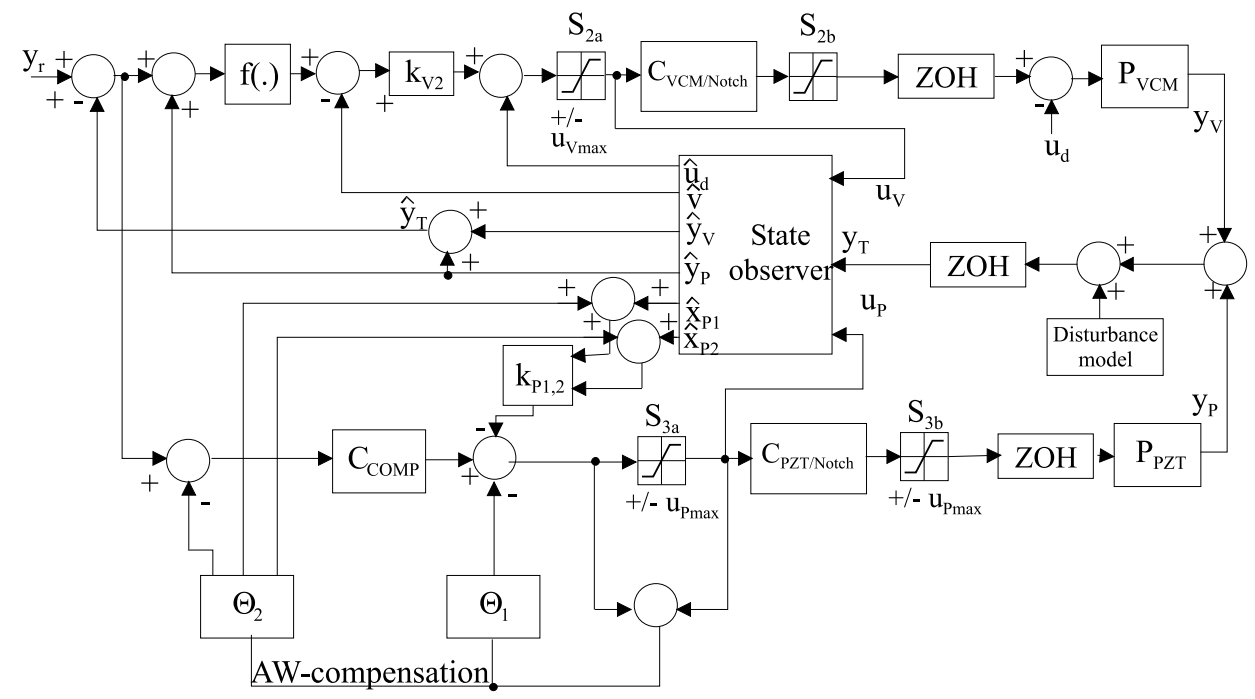

Fig. 17. Modified control scheme with observer and AW-compensation 


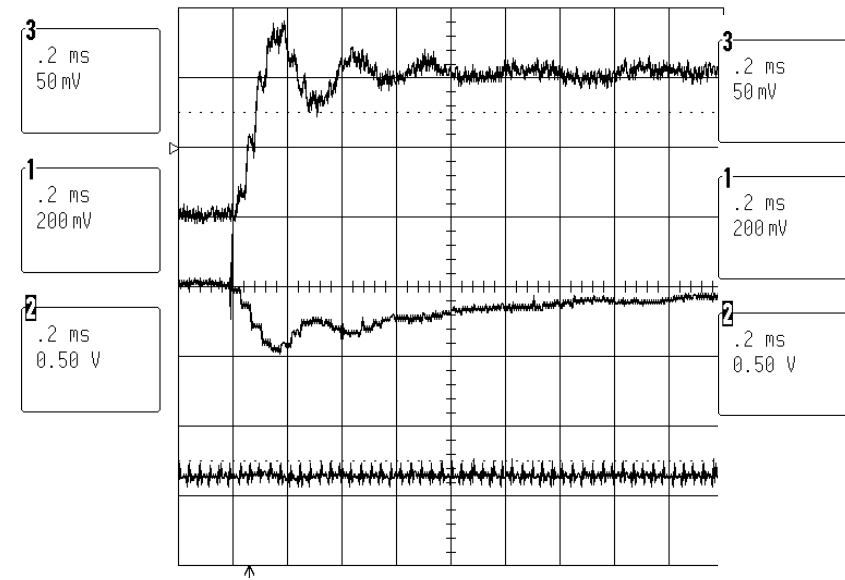

(a) Linear nominal control

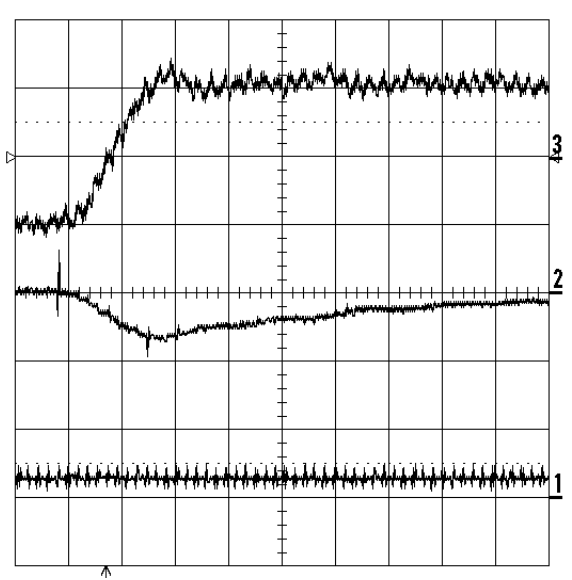

(b) Hredzak et al. (2006)-scheme

Fig. 18. Step response of $200 \mathrm{~nm}$; ch3(top): LDV-measurement $(2 \mu \mathrm{m} / \mathrm{V})$, ch2(middle): PZT-amplifier input, ch1(bottom): VCM-driver input 


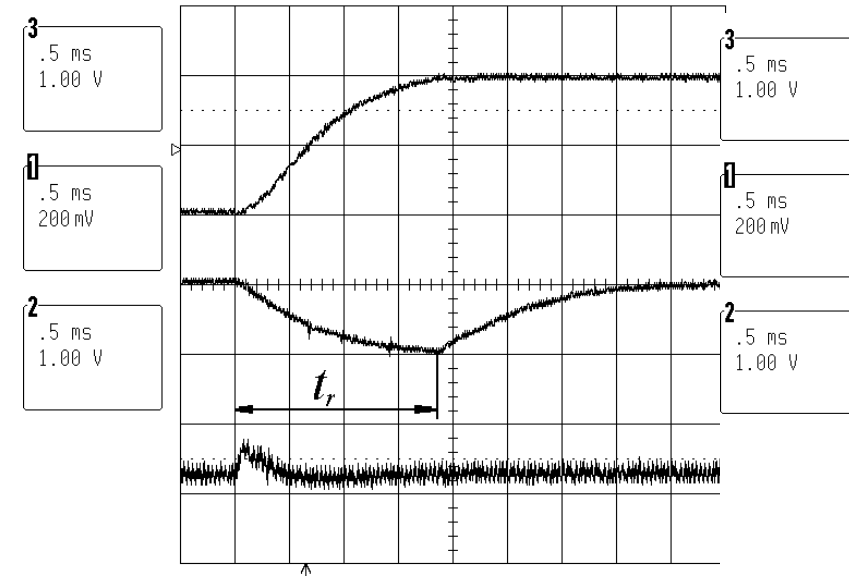

(a) Hredzak et al. (2006)-scheme

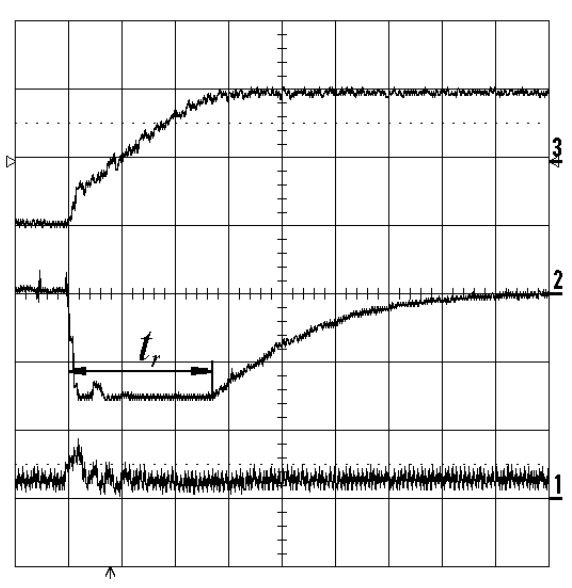

(b) AW-scheme

Fig. 19. Step response of $4 \mu m$; ch3(top): LDV-measurement $(2 \mu \mathrm{m} / \mathrm{V})$, ch2(middle): PZT-amplifier input, ch1(bottom): VCM-driver input 


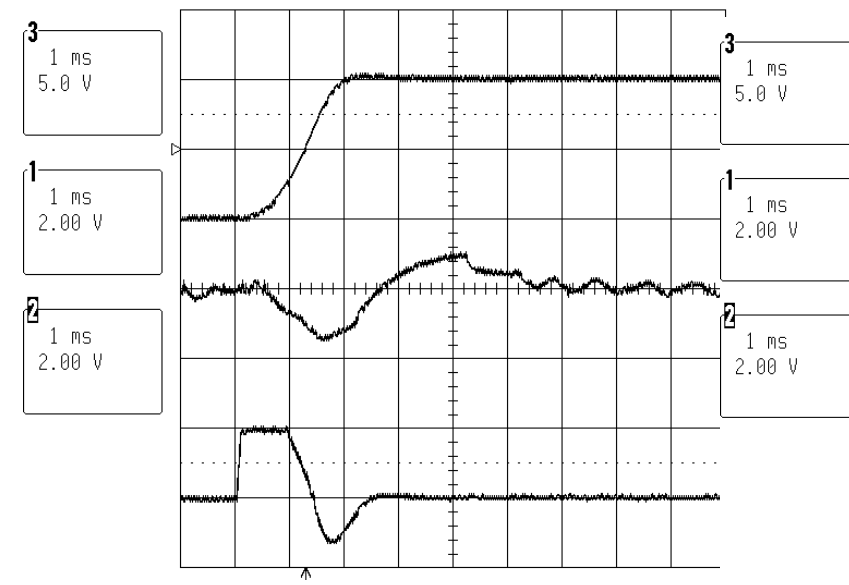

(a) Hredzak et al. (2006)-scheme

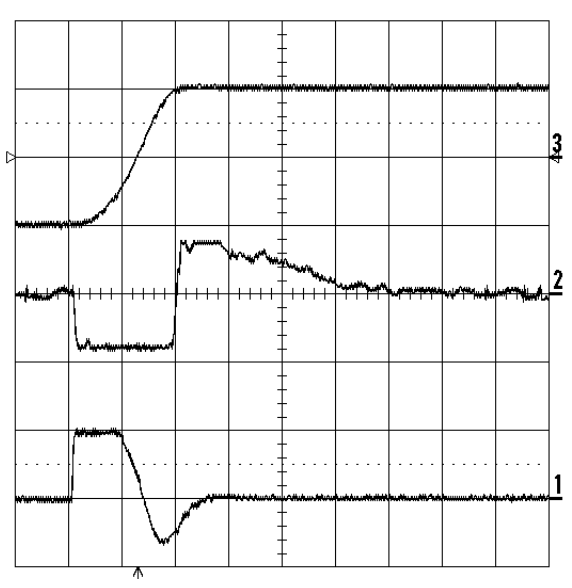

(b) AW-Scheme

Fig. 20. Step response of $200 \mu m$; ch3(top): LDV-measurement $(20 \mu \mathrm{m} / \mathrm{V})$, ch2(middle): PZT-amplifier input, ch1(bottom): VCM-driver input 


\section{Biographies}

Ian Postlethwaite was born in Wigan, England in 1953. He received a First Class BSc (Eng) degree from Imperial College, London University in 1975 and the $\mathrm{PhD}$ degree from Cambridge University in 1978.

From 1978 to 1981 he was a Research Fellow at Cambridge University and spent six months at General Electric Company, Schenectady, USA. In 1981, he was appointed to a Lectureship in Engineering Science at Oxford University. In 1988, he moved to a Chair of Engineering at the University of Leicester where he was Head of Department from 1995-2004 and is now a Pro-Vice-Chancellor. He has held visiting research positions at the Australian National University and the University of California at Berkeley. His research involves theoretical contributions to the field of robust multivariable control and the application of advanced control system design to engineering systems.

He is a Fellow of the Royal Academy of Engineering, the IEEE, the IET and the InstMC. In 1991, he received the IEE FC Williams premium; in 2001, he was awarded the Sir Harold Hartley Medal of the InstMC; and in 2002, he received a best paper prize from the IFAC Journal of Control Engineering Practice. He is a co-author with Sigurd Skogestad of Multivariable Feedback Control (Wiley, 1996 and 2005).

Matthew Turner was born in Corby, England in 1975. He received the BEng degree in Electrical and Electronic Engineering in 1996, from the University of Surrey, and the $\mathrm{PhD}$ in Control Engineering in 2000, from the University of Leicester. His main research interests are centred around robust control, flight control and the control of systems containing isolated nonlinearities. He has designed and implemented robust controllers and anti-windup compensators on several industrial engineering systems and is currently involved with the European aerospace group, GARTEUR, in investigating the phenomenon of pilot-induced-oscillations.

Guido Herrmann was born in Berlin, Germany in 1972. He received the German degree 'Diplom-Ingenieur der Elektrotechnik' (with highest honours) from the Technische Universitaet zu Berlin, Germany, and the PhD-degree from the University of Leicester, U.K., in 1997 and 2001 respectively. For his PhD, he was sponsored first by the Daimler-Benz-Foundation/Germany and later by a MarieCurie Fellowship. From 2001 to 2003, he was a Senior Research Fellow at the A*STAR Data Storage Institute in Singapore. From 2003 until 2005, he was a Research Associate at the University of Leicester followed by a one-year secondment as a lecturer at the University of Leicester. Guido Herrmann will be joining the University of Bristol as a Lecturer in Dynamics in March 2007. His research interests are in the theory and application of non-linear and robust control in particular sampled-data, anti-windup, sliding-mode, and $\mathrm{NN}$-control as well as regulation of chaotic systems. 